\begin{tabular}{|c|c|}
\hline Title & $\begin{array}{l}\text { Identification of mutagenic transformation products generated during oxidation of } 3 \text { methyl- } 4 \text { - nitrophenol solutions by } \\
\text { orbitrap tandem mass spectrometry and quantitative structure activity relationship analyses }\end{array}$ \\
\hline Author(s) & $\begin{array}{l}\text { Matsushita, Taku; Honda, Shiho; Kuriyama, Taisuke; Fujita, Y uki; Kondo, Takashi; Matsui, Y oshihiko; Shirasaki, } \\
\text { Nobutaka; T akanashi, Hirokazu; Kameya, Takashi }\end{array}$ \\
\hline Citation & $\begin{array}{l}\text { Water research, 129, 347-356 } \\
\text { https://doi.org/10.1016/.watres.2017.11.033 }\end{array}$ \\
\hline Issue Date & 2018-02-01 \\
\hline Doc URL & http:/hdl .handle.net/2115/76643 \\
\hline Rights & $\begin{array}{l}\text { () 2018. This manuscript version is made available under the CC-BY-NC-ND } 4.0 \text { license } \\
\text { http://creativecommons.org/icenses/by-nc-nd/4.0/ }\end{array}$ \\
\hline Rights(URL) & http://creativecommons.org/icenses/by-nc-nd/4.0/ \\
\hline Type & article (author version) \\
\hline File Information & WR_3M 4NP_for-HUSCAP.PDF \\
\hline
\end{tabular}

Instructions for use 


\title{
Identification of mutagenic transformation products generated during oxidation of 3-methyl-4-nitrophenol solutions by orbitrap tandem mass spectrometry and quantitative structure-activity relationship analyses
}

\author{
Taku Matsushita ${ }^{1 *}$, Shiho Honda ${ }^{2}$, Taisuke Kuriyama², Yuki Fujita ${ }^{2}$, Takashi Kondo ${ }^{2}$, \\ Yoshihiko Matsui ${ }^{1}$, Nobutaka Shirasaki ${ }^{1}$, Hirokazu Takanashi ${ }^{3}$ and Takashi Kameya ${ }^{4}$ \\ ${ }^{1}$ Faculty of Engineering, Hokkaido University, N13W8, Sapporo 060-8628, Japan \\ ${ }^{2}$ Graduate School of Engineering, Hokkaido University, N13W8, Sapporo 060-8628, Japan \\ ${ }^{3}$ Faculty of Science and Engineering, Kagoshima University, 1-21-40 Korimoto, Kagoshima 890-0065, Japan
}

${ }^{4}$ Faculty of Environment and Information Sciences, Yokohama National University, 79-7 Tokiwadai, Hodogaya, Yokohama 240-8501, Japan

*Corresponding author: taku-m@eng.hokudai.ac.jp, +81-11-706-7279

\begin{abstract}
We used Ames assays to investigate the effects of ozonation (designated $\mathrm{O}_{3}$ ), ozonation followed by chlorination $\left(\mathrm{O}_{3} / \mathrm{Cl}\right)$, an advanced oxidation process $\left(\mathrm{AOP}, \mathrm{UV} / \mathrm{H}_{2} \mathrm{O}_{2}\right)$, and $\mathrm{AOP}$ followed by chlorination $(\mathrm{AOP} / \mathrm{Cl})$ on the mutagenicity of solutions of 3-methyl-4-nitrophenol (3M4NP), a major environmental degradation product of the organophosphorus insecticide fenitrothion. Whereas $\mathrm{O}_{3}$ did not induce mutagenicity, $\mathrm{O}_{3} / \mathrm{Cl}$, AOP, and $\mathrm{AOP} / \mathrm{Cl}$ converted 3M4NP into mutagenic transformation products (TPs). Using liquid chromatography-mass spectrometry, we detected a total of 138 peaks in the solutions subjected to $\mathrm{O}_{3} / \mathrm{Cl}$, AOP, and $\mathrm{AOP} / \mathrm{Cl}$. To elucidate the TPs responsible for the observed mutagenicity, we performed simple regression analyses of the relationship between the area of each peak and the observed mutagenicity of samples withdrawn periodically during each oxidation process. The area of each of 10 peaks was found to be positively correlated $\left(r^{2} \geq 0.8\right)$ with the observed mutagenicity, suggesting that the TPs corresponding to these peaks contributed to the mutagenicity. After taking into account the consistency of mutagenicity induction by the oxidation processes and analyzing the peaks by tandem mass spectrometry, we identified 3 TPs, corresponding to 6 peaks, as candidate mutagens. These TPs were assessed by means of 4 quantitative structure-activity relationship (QSAR) models, and all 3 were predicted to be mutagenic by at least one model. This result was consistent with our assumption that these TPs were mutagens. Ames assays of an authentic sample of one of the 3 TPs revealed that it did not contribute to the mutagenicity. This left 3-methoxy-4-nitrophenol and 2-[(E)-[(2,5dihydroxyphenyl) methylidene]amino]-5-dihydroxybenzaldehyde on the list of mutagens suspected of contributing to the mutagenicity induced by AOP. No TPs were identified as candidate mutagens responsible for the mutagenicity induced by $\mathrm{O}_{3} / \mathrm{Cl}$ and $\mathrm{AOP} / \mathrm{Cl}$.
\end{abstract}

Keywords: Advanced oxidation process; Ames assay; chlorination; fenitrothion; ozonation; toxicity. 


\section{Introduction}

After pesticides are applied to agricultural fields, they are converted into various transformation products (TPs) by means of biotic and abiotic degradation processes such as biodegradation and photodegradation (Sinclair et al. 2006). Because TPs are often lower in molecular weight and more polar than their parent compounds, TPs tend to run off into environmental waters more readily (Fenner et al. 2013). In fact, some TPs are known to be more abundant in aquatic environments than their parent compounds (Escher and Fenner 2011). If run-off effluents are present in raw water entering drinking water treatment plants, the possible risks arising from the presence of TPs in the finished water must be considered, especially because some TPs are more toxic than their parent compounds (Fenner et al. 2013, Takanashi et al. 2014).

TPs are generated not only in the environment but also during water treatment processes, and the latter phenomenon has been the focus of recent research (Escher and Fenner 2011). For example, 3-methyl-4nitrophenol (3M4NP), a major TP of the widely used organophosphorus insecticide fenitrothion $(\mathrm{O}, \mathrm{O}-$ dimethyl $O$-(3-methyl-4-nitrophenyl) phosphorothioate), may be transformed into mutagenic compounds during water treatment (Kishida et al. 2010), even though 3M4NP does not show mutagenicity in the Ames assay (Miyamoto et al. 1978, Hara et al. 1989). Fenitrothion is readily degraded to 3M4NP in soil under aerobic conditions (Takimoto et al. 1976, Spillner et al. 1979, Adhya et al. 1981, Mikami et al. 1985b, Misra et al. 1993) as well as by sunlight-induced photodegradation both in river water and on the soil surface (Ohkawa et al. 1974, Mikami et al. 1985a, Matsushita et al. 2006). Therefore, raw water entering drinking water treatment plants located downstream of fenitrothion-treated fields may be contaminated with 3M4NP. In fact, 3M4NP has frequently been detected in the water of rivers that receive run-off from agricultural fields treated with fenitrothion. Specifically, Kameya et al. (2012) monitored 3M4NP and fenitrothion concentrations in river water in Japan (109 samples collected at 41 observation points in 12 rivers) and detected 3M4NP in $32 \%$ of the samples; the $3 \mathrm{M} 4 \mathrm{NP}$ concentrations were equal to or larger than the fenitrothion concentrations in $45 \%$ of the samples in which fenitrothion, 3M4NP, or both were detected.

Because low-molecular weight contaminants such as 3M4NP are generally difficult to remove by conventional drinking water treatment processes involving coagulation, sedimentation, and sand filtration, 3M4NP is still present when chlorine is added for disinfection of the finished water and probably reacts with the chlorine. In fact, Kishida et al. (2010) reported that a 3M4NP solution became mutagenic after the addition of free chlorine, indicating that 3M4NP is transformed into a mutagenic compound or compounds during chlorination. Takanashi et al. (2012) reported that chloro-5-hydroxy-2-nitrobenzoic acid $(\mathrm{C} 5 \mathrm{H} 2 \mathrm{NBA})$ is largely responsible for the mutagenicity induced by chlorination of 3M4NP solutions. Moreover, Kishida et al. (2010) reported that the mutagenicity of a chlorinated 3M4NP solution is much higher than that of a chlorinated fenitrothion solution at the same molar concentration. This result indicates that more attention should be paid to 3M4NP-derived TPs than to fenitrothion-derived TPs when the mutagenicity of finished water is evaluated.

From the viewpoint of drinking water safety, the mutagenicity of finished water must be low, and therefore a method for removal of 3M4NP from water before chlorination is highly desirable. Ozonation and advanced oxidation processes (AOPs) are known to effectively decompose organic micropollutants, but 
direct application of these methods for 3M4NP decomposition has not yet been reported. In addition, 3M4NP is likely to be transformed into various TPs during such processes, and it is unlikely that all of the resulting TPs are nontoxic. Therefore, investigation of the toxicity of TPs generated from 3M4NP during water treatment is necessary to ensure the safety of finished drinking water.

Accordingly, we had 3 objectives for the present study. The first was to investigate whether 3M4NP was decomposed by means of 4 oxidation processes: ozonation (designated $\mathrm{O}_{3}$ ), $\mathrm{O}_{3}$ followed by chlorination (designated $\mathrm{O}_{3} / \mathrm{Cl}$ ), UV irradiation in the presence of $\mathrm{H}_{2} \mathrm{O}_{2}$ (AOP), and AOP followed by chlorination $(\mathrm{AOP} / \mathrm{Cl})$. The second objective was to investigate changes in the mutagenicity of 3M4NP solutions induced by these processes, and the third objective was to identify TPs that contributed to the oxidationinduced mutagenicity. We began by subjecting 3M4NP solutions to the 4 oxidation processes on a laboratory scale in batch mode. We used Ames assays to assess the mutagenicity of samples periodically withdrawn during each process. Candidate TPs suspected of contributing to any observed mutagenicity were elucidated by means of regression analysis of the relationship between observed mutagenicity and TP peak areas in chromatograms obtained by liquid chromatography (LC). The chemical formulas of the TPs corresponding to each of the LC peaks were determined by tandem mass spectrometry (MS/MS). Finally, the mutagenicity of each of the candidate TPs was predicted by means of 4 quantitative structure-activity relationship (QSAR) models.

\section{Materials and Methods}

\subsection{Batch $\mathrm{O}_{3}$ experiments}

Phosphate buffer (12 L, 5 mM, pH 7.0) was prepared with Milli-Q water (Milli-Q Advantage, Millipore Co.,
Bedford, MA, USA) in a glass vessel, and then ozone gas was bubbled into the solution at a constant flow rate of $0.3 \mathrm{mg}$-ozone/(L·min) for $60 \mathrm{~min}$ by means of a laboratory-scale ozone generator (Pretty $\mathrm{O}_{3}$, Metawater Co., Tokyo, Japan). Then 3M4NP was added to the vessel at a concentration of approximately $12 \mathrm{mg} / \mathrm{L}$, and $\mathrm{O}_{3}$ was continued at the same flow rate. During $\mathrm{O}_{3}$, samples $(2 \mathrm{~L})$ were withdrawn from the vessel at 0,5 , 10, 20, and $30 \mathrm{~min}$. Each 2-L sample was evenly divided into 2 parts. One part (1 L) was chlorinated without quenching residual $\mathrm{O}_{3}$ as described in section 2.3. The other part $(1 \mathrm{~L})$ was subjected to solid-phase extraction with Sep-Pak PS2 cartridges (Nihon Waters K. K., Tokyo, Japan) to obtain a 100-times concentrate in of acetone. Some of the concentrate was used for quantification of 3M4NP and investigation of the TPs formed from it during $\mathrm{O}_{3}$. The remainder of the eluate was dehydrated over anhydrous sodium sulfate, and then evaporated to dryness under flowing nitrogen gas in a water bath at $45^{\circ} \mathrm{C}$. The residue was dissolved in dimethyl sulfoxide to obtain a 250-times concentrate, which was then subjected to the mutagenicity assays (section 2.6).

\subsection{Batch AOP experiments}

In a glass vessel, 3M4NP was dissolved at a concentration of approximately $9 \mathrm{mg} / \mathrm{L}$ in $72 \mathrm{~L}$ of phosphate buffer $(5 \mathrm{mM}, \mathrm{pH}$ 7.0) prepared with MilliQ water, and then $\mathrm{H}_{2} \mathrm{O}_{2}(100 \mathrm{mg} / \mathrm{L})$ was added. The resulting solution was evenly divided into $3 \mathrm{~L}$ portions that were placed in one of 24 glass vessels, four of each for subsequent irradiation for $0,10,20,40,60$, or 120 min. Each solution was stirred rapidly with a magnetic stirrer during irradiation with a low-pressure mercury lamp (NNI 60/35XL, Heraeus Holding GmbH, Hanau, Germany; $\lambda=254 \mathrm{~nm}, 65 \mathrm{~W}$ ) at a distance of $6.5 \mathrm{~cm}$ for the desired duration (Fig. S1). After irradiation, $6 \mathrm{~L}$ of the solution at each irradiation time was chlorinated without quenching residual $\mathrm{O}_{3}$ as described in section 
2.3, and $5 \mathrm{~L}$ at each irradiation time was subjected to solid-phase extraction with a Sep-Pak PS2 cartridge to obtain a 100-times concentrate in acetone. Some of the concentrate was used for quantification of 3M4NP and investigation of its TPs. The other part of the eluate was dehydrated over anhydrous sodium sulfate, and evaporated to dryness under flowing nitrogen gas in a water bath at $45{ }^{\circ} \mathrm{C}$. The residue was dissolved in dimethyl sulfoxide to obtain a 250-times concentrate, which was subjected to the mutagenicity assay (section 2.6).

\subsection{Batch chlorination experiments}

Samples generated in the batch $\mathrm{O}_{3}$ and AOP experiments (sections 2.1 and 2.2, respectively) were supplemented with enough sodium hypochlorite to achieve a residual free chlorine concentration of $0.1-1.0 \mathrm{mg}-\mathrm{Cl}_{2} / \mathrm{L}$ after $24 \mathrm{~h}$. After $24 \mathrm{~h}$ of chlorination, the residual chlorine was quenched with 1.2 equiv of sodium sulfite. The resulting solutions were subjected to solid-phase extraction with Sep-Pak PS2 cartridges to obtain 100-times concentrates in acetone. Some of each concentrate was used for quantification of 3M4NP and investigation of its TPs. The rest of the concentrate was dehydrated over anhydrous sodium sulfate, and evaporated to dryness under flowing nitrogen gas in a water bath at $45{ }^{\circ} \mathrm{C}$. The residue was dissolved in dimethyl sulfoxide to obtain a 250 -times concentrate, which was subjected to the mutagenicity assay (section 2.6).

\subsection{Derivatization of TPs in LC/MS samples}

To facilitate ionization during LC/MS analysis, a portion of each sample set aside for LC/MS analysis was derivatized with 2-hydrazinopyridine as follows. A stock solution of 2-hydrazinopyridine $(10 \mathrm{mmol} / \mathrm{L})$ in acetonitrile was prepared. Forty microliters of each of the 100-times concentrates obtained as described in sections 2.1-2.3 was evaporated to dryness under flowing nitrogen gas in a water bath at $45^{\circ} \mathrm{C}$, and the residue was dissolved in $3350 \mu \mathrm{L}$ of acetonitrile. Each solution was then supplemented with $650 \mu \mathrm{L}$ of the 2hydrazinopyridine stock solution and incubated at $75{ }^{\circ} \mathrm{C}$ with shaking for $4 \mathrm{~h}$. After incubation, the samples were evaporated to dryness under flowing nitrogen gas in a water bath at $45^{\circ} \mathrm{C}$, and the residue was dissolved in the $4000 \mu \mathrm{L}$ of methanol. By means of this derivatization procedure, any TPs having carbonyl groups were derivatized so that they would undergo ionization in both the negative- and the positive-ion modes; therefore, they could be detected in either mode or both (Higashi et al. 2010, Hala et al. 2011).

\subsection{Quantification of $3 M 4 N P$ and identification of its} TPS

3M4NP was quantified and its TPs were identified by means of a hybrid quadrupole-orbitrap mass spectrometer (Q-Exactive, Thermo Fisher Scientific Inc., Waltham, MA, USA) coupled with a LC system (UltiMate 3000, Thermo Fisher Scientific Inc.). Five microliters of each sample solution was used for LC on a $50 \mathrm{~mm} \times 2.1 \mathrm{~mm}$ Hypersil Gold column $(1.9 \mu \mathrm{m}$ particle size, Thermo Fisher Scientific Inc.). The mobile phase was a binary gradient of $2 \mathrm{mM}$ ammonium formate in Milli-Q water (solvent A) and $100 \%$ methanol (solvent B) at a flow rate of 200 $\mu \mathrm{L} / \mathrm{min}$ as follows: 99:1 (v/v) A/B for 2 min, increase linearly to $60 \% \mathrm{~B}$ over a period of $2 \mathrm{~min}$, increase linearly to $75 \% \mathrm{~B}$ over a period of $6 \mathrm{~min}$, increase linearly to $99 \%$ B over a period of $5 \mathrm{~min}$, and then hold at that ratio for $0.1 \mathrm{~min}$. MS was performed in electrospray ionization mode with a spray voltage of $2.0 \mathrm{kV}$. The temperatures of the capillary and the electrospray ionization probe heater were 220 and $450{ }^{\circ} \mathrm{C}$, respectively. The flow rates of the sheath gas, auxiliary gas, and sweep gas were 50, 15 and 0 units, respectively. The S-lens ratio frequency level was set at 
78. 3M4NP was quantified in targeted selected-ionmonitoring mode (resolution $=70,000)$ in negative-ion mode; the fragment ion of interest occurred at $\mathrm{m} / \mathrm{z}=$ 152.0353 .

The TPs were analyzed under the LC conditions described for 3M4NP quantification. Two measurement modes were used for TP identification: scan mode (resolution $=70,000$, scan range $=50-500$ $\mathrm{m} / \mathrm{z}$ ) and targeted MS/MS mode (resolution = 70,000, collision energy $=10-50 \mathrm{eV}$ ) in both positive- and negative-ion modes.

\subsection{Mutagenicity assays}

The mutagenicities of the samples were evaluated by means of Ames assays performed in the absence or presence of a rat liver activation system (S9 mix) with a 20-min preincubation period, as described by Maron and Ames (1983). Oxoid nutrient broth no. 2 was used for the overnight cultures. Because tap waters undergoing chlorination tend to induce mutagenicity in TA100 (Vartiainen and Liimatainen, 1986; Park et al., 2000; Takanashi et al., 2009) and 3M4NP-containing solution reportedly induced mutagenicity after chlorination in TA100 (Kishida et al., 2010), we used TA100 (NBRC 14194) for detecting base-pairsubstitution-type mutagenicity in the present study. For use in detecting frameshift-type mutagenicity, we selected TA98 (NBRC 14193) which possesses the same characteristics (defective lipopolysaccharide layer $(r f a)$ and introduction of ampicillin resistance (pKM101)) as TA100 except for types of detectable mutagenicity. These Salmonella typhimurium strains were purchased from the Biological Resource Center, National Institute of Technology and Evaluation (NBRC, Kisarazu, Japan). For both strains, 2aminoanthracene and 2-nitrofluorene were used as positive controls with and without metabolic activation, respectively, and dimethyl sulfoxide was used as a negative control under all conditions. Revertant colonies (His $^{+}$revertants) were counted after incubation at $37{ }^{\circ} \mathrm{C}$ for $48 \mathrm{~h}$. The number of $\mathrm{His}^{+}$ revertants in each sample is reported as a mean from 2 plates. To quantify the magnitude of mutagenicity, we calculated a mutagenicity intensity (MI):

$$
\mathrm{MI}=\frac{n-n_{0}}{n_{0}}
$$

where $n$ is the number of $\mathrm{His}^{+}$revertants per plate, and $n_{0}$ is the number of spontaneous revertants per plate. To facilitate comparison, we standardized the mutagenicity of each sample by using a $\mathrm{MI}_{500}$ value, which we defined as the MI at the dose of sample solution that initially contained $500 \mu \mathrm{g}$ of $3 \mathrm{M} 4 \mathrm{NP}$ before any treatment. We calculated the $\mathrm{MI}_{500}$ values by interpolation from the regression line using the linearly increasing part of the dose-response curve of the Ames assay for each sample.

\subsection{QSAR analyses}

To evaluate the Ames Salmonella mutagenicity of the TPs identified by MS/MS analysis, we conducted QSAR analyses by using 4 types of freely available QSAR software: Toxtree (version 2.6.6, Ideaconsult, Sofia, Bulgaria, http://toxtree.sourceforge.net/); CAESAR (version 2.1.12, developed as part of the European Union-funded CAESAR project), used on the VEGANIC platform (version 1.0.8, http://www. vega-qsar.eu/); Lazar (In Silico Toxicology $\mathrm{GmbH}$, Basel, Switzerland, http://www.in-silico.ch/); and T.E.S.T. (version 4.1, United States Environmental Protection Agency, http://www.epa.gov/nrmrl/std/qsar/ qsar.html). T.E.S.T. includes 4 types of QSAR methods (hierarchical method, FDA method, nearest neighbor method, and consensus method) for predicting Salmonella mutagenicity. In the present study, we used the consensus method because it provided the best prediction results during external validation according 
to the manufacturer's guide. The QSAR models used in the present study predicted Salmonella mutagenicity in the absence and presence of metabolic activation, because the datasets for the models consisted of mutagenicity data obtained in the absence and presence of metabolic activation (Zeiger 1987, Kazius et al. 2005, Hansen et al. 2009).

\section{Results and Discussion}

\subsection{Change in 3M4NP concentration during oxidation}

\section{treatments}

3M4NP gradually decomposed during $\mathrm{O}_{3}$ and was completely consumed after $30 \mathrm{~min}$ (white circles, Fig. 1a). Decomposition of $3 \mathrm{M} 4 \mathrm{NP}$ by $\mathrm{O}_{3}$ has not previously been reported, but its parent compound, fenitrothion, has been reported to be decomposed by ozone (Koga et al. 1992).

3M4NP was also decomposed by AOP and was completely consumed after 60 min (white circles, Fig. 1b). Although the use of AOP directly on 3M4NP has not been reported, Kormali et al. (2004) found that $3 \mathrm{M} 4 \mathrm{NP}$ is produced during photocatalyst-based AOP of fenitrothion and is decomposed by further AOP, which is consistent with our results.
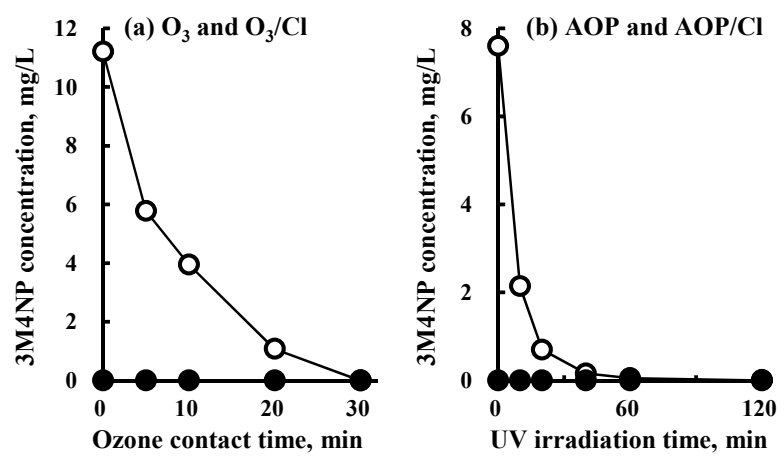

Fig. 1 Changes in 3-methyl-4-nitrophenol (3M4NP) concentration with ozone contact time during (a) $\mathrm{O}_{3}$ and $\mathrm{O}_{3} / \mathrm{Cl}$ and with $\mathrm{UV}$ irradiation time during (b) $\mathrm{AOP}$ and $\mathrm{AOP} / \mathrm{Cl}$ before (white circles) and after (black circles) chlorination. The chlorination duration was $24 \mathrm{~h}$ for all experiments.

When samples subjected to $\mathrm{O}_{3}$ and $\mathrm{AOP}$ were subsequently chlorinated, no 3M4NP was detected after $24 \mathrm{~h}$, regardless of the $\mathrm{O}_{3}$ and AOP treatment times (black circles, Figs. 1a and 1b). Takanashi et al. (2012) have reported that 3M4NP is decomposed by contact with chlorine, and our results are consistent with this finding. However, after the chlorination process, $\geq 4$ and $\geq 3 \mathrm{mg} / \mathrm{L}$ of dissolved organic carbon were detected in the $\mathrm{O}_{3} / \mathrm{Cl}$ and $\mathrm{AOP} / \mathrm{Cl}$ samples, respectively (data not shown), which indicates that some organic TPs remained in the samples.

\subsection{Change in mutagenicity of $3 M 4 N P$ solutions during}

$\mathrm{O}_{3}$ and $\mathrm{O}_{3} / \mathrm{Cl}$

We evaluated the changes in mutagenicity of 3M4NP solutions during $\mathrm{O}_{3}$ and $\mathrm{O}_{3} / \mathrm{Cl}$ (Fig. 2). Before either $\mathrm{O}_{3}$ or chlorination (white circles at an ozone contact time, $t$, of 0 ), no mutagenicity was observed regardless of the Ames assay conditions used, because 3M4NP is not a mutagen (Miyamoto et al. 1978, Hara et al. 1989, Kishida et al. 2010). Even after $\mathrm{O}_{3}$, the $3 \mathrm{M} 4 \mathrm{NP}$ solution showed no mutagenicity, indicating that 3M4NP was transformed into nonmutagenic TPs during $\mathrm{O}_{3}$.

In contrast, after the 3M4NP solution was treated with chlorine alone (black circles at $t=0$ ), mutagenicity was observed in the TA98 assay with metabolic activation and in TA100 assays without and with metabolic activation. Chlorination of a 3M4NP solution has previously been reported to induce mutagenicity (Kishida et al. 2010, Takanashi et al. 2012), which is consistent with our results.

When a 3M4NP-containing solution was subjected to $\mathrm{O}_{3}$ before chlorination, the final mutagenicity after chlorination depended on the conditions of the Ames assay. In the TA98 assay without metabolic activation, mutagenicity slightly increased with increasing $\mathrm{O}_{3}$ time (Fig. 2e), indicating that mutagenic TPs were generated from TPs produced during $\mathrm{O}_{3}$ prior to chlorination. Hereafter, TPs generated during $\mathrm{O}_{3}$ and AOP are 


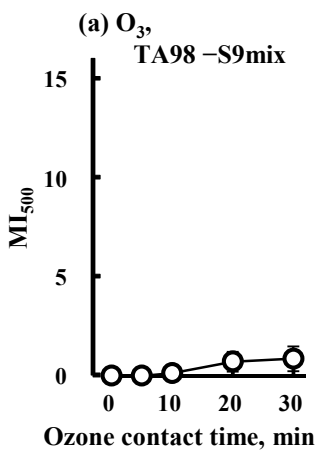

(e) $\mathrm{O}_{3} / \mathrm{Cl}$,

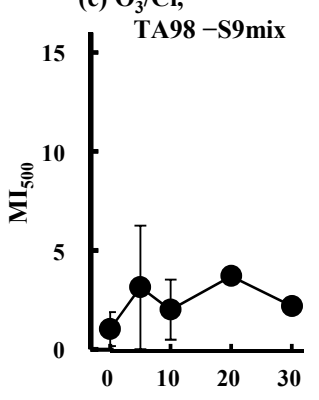

Ozone contact time, $\min$ (b) $\mathbf{O}_{3}$,

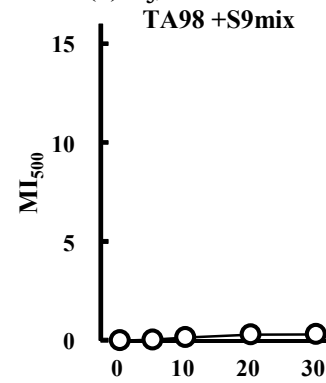

Ozone contact time, min

(f) $\mathrm{O}_{3} / \mathrm{Cl}$,

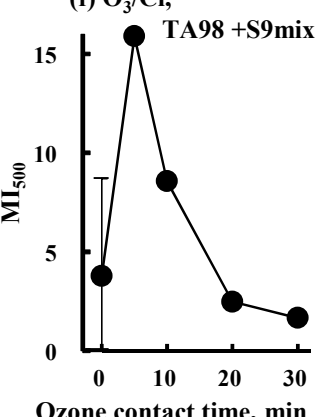

(c) $\mathbf{O}_{3}$,

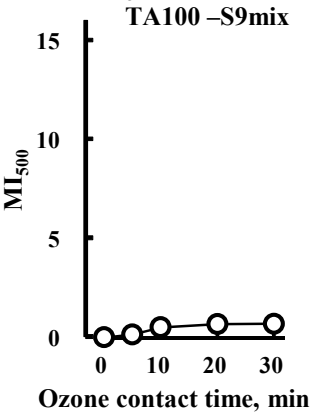

(g) $\mathrm{O}_{3} / \mathrm{Cl}$,

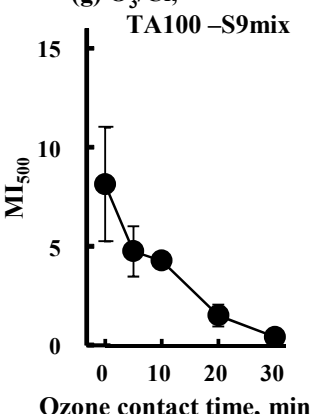

(d) $\mathbf{O}_{3}$,

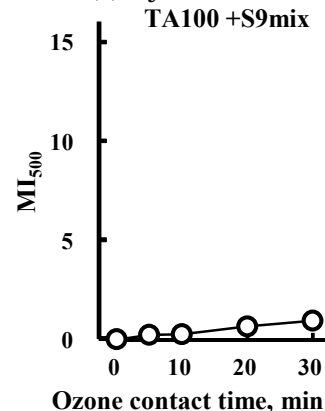

(h) $\mathrm{O}_{3} / \mathrm{Cl}$,

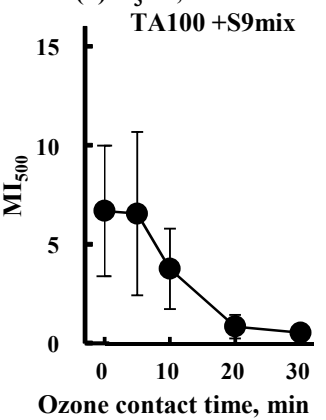

Fig. 2 Effect of ozone contact time on mutagenicity intensity $\left(\mathrm{MI}_{500}\right)$ of 3-methyl-4-nitrophenol solutions before and after chlorination: $\mathrm{O}_{3}$ (white circles) and $\mathrm{O}_{3} / \mathrm{Cl}$ (black circles), without (-S9mix) and with ( $\left.+\mathrm{S} 9 \mathrm{mix}\right)$ metabolic activation in the Ames assay. The chlorination duration was $24 \mathrm{~h}$ for all experiments. $\mathrm{MI}_{500}$ is defined as mutagenicity intensity $(\mathrm{MI}=(n-$ $\left.n_{0}\right) / n_{0}$, where $n$ is the number of $\mathrm{His}^{+}$revertants per plate, and $n$ is the number of spontaneous revertants per plate) at the dose of sample solution that had initially contained $500 \mu \mathrm{g}$ of 3-methyl-4-nitrophenol before $\mathrm{O}_{3}$. Error bars indicate standard deviations of at least 2 measurements.

referred to as OTPs, and TPs generated during subsequent chlorination are referred to as COTPs. The TPs generated from 3M4NP by chlorination alone are referred to as CTPs. The mutagenic COTPs detected in the TA98 assay without metabolic activation were generated from some of the OTPs.

In the TA98 assay with metabolic activation, mutagenicity after chlorination was high at an $\mathrm{O}_{3}$ duration of $5 \mathrm{~min}$ and then decreased with increasing $\mathrm{O}_{3}$ duration (Fig. 2f). These results suggest that precursors of mutagenic COTPs were generated within 5 min of $\mathrm{O}_{3}$, but that as $\mathrm{O}_{3}$ treatment was continued, these precursors were gradually transformed into OTPs that were not subsequently transformed into mutagenic COTPs by chlorination.

In contrast, in TA100 assays without and with metabolic activation (Fig. 2g,h, respectively), mutagenicity induced by the chlorination process alone decreased with $\mathrm{O}_{3}$ duration. The result suggests that during $\mathrm{O}_{3}$, precursors of mutagenic CTPs were transformed into OTPs that were not subsequently transformed into mutagenic COTPs by chlorination. Overall, from a practical standpoint, $\mathrm{O}_{3}$ prior to chlorination effectively reduced the risk of exposure to mutagenic TPs eventually produced by chlorination of the ozonized 3M4NP solution.

\subsection{Change in mutagenicity of 3M4NP solutions during $A O P$ and $A O P / C l$}

We evaluated the change in mutagenicity of $3 \mathrm{M} 4 \mathrm{NP}$ solutions during $\mathrm{AOP}$ and $\mathrm{AOP} / \mathrm{Cl}$ (Fig. 3). As expected, no mutagenicity was observed before the treatments, but after AOP treatment for $10 \mathrm{~min}$, high mutagenicity was observed in TA98 and TA100 assays without metabolic activation (Fig. 3a,c, respectively), and slight mutagenicity was observed in the TA98 assay with metabolic activation (Fig. 3b). These results clearly indicate that mutagenic OTPs were generated 
(a) AOP,

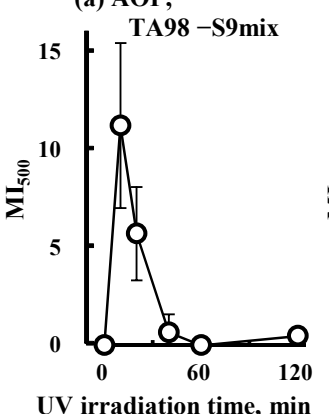

(e) $\mathrm{AOP} / \mathrm{Cl}$,

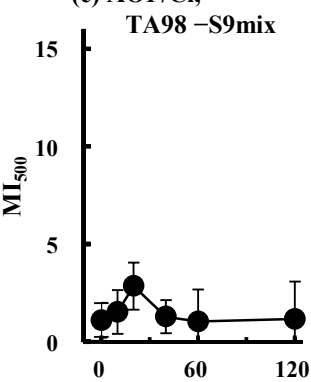

UV irradiation time, min (b) AOP,

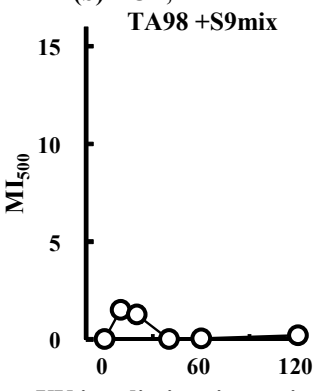

UV irradiation time, min

(f) $\mathrm{AOP} / \mathrm{Cl}$,

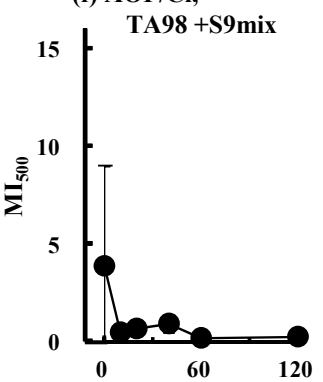

UV irradiation time, min (c) AOP,

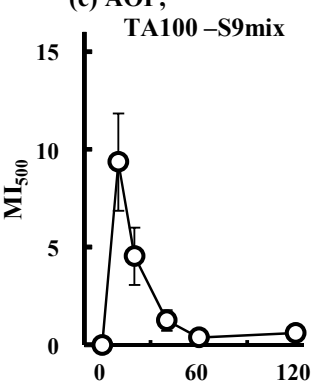

UV irradiation time, min

(g) $\mathrm{AOP} / \mathrm{Cl}$,

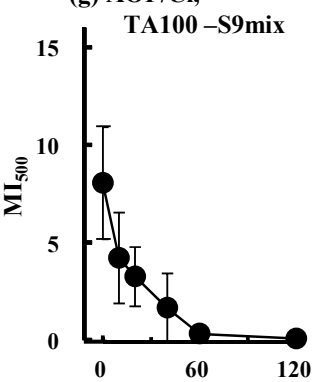

UV irradiation time, min (d) AOP,

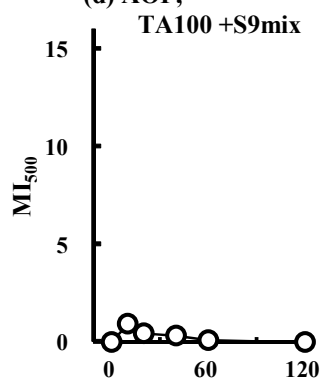

UV irradiation time, min

(h) $\mathrm{AOP} / \mathrm{Cl}$,

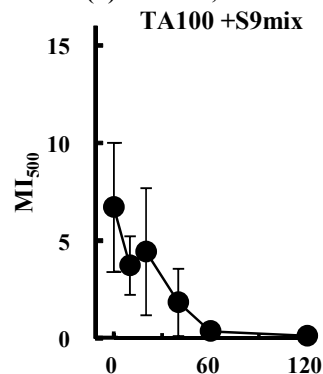

UV irradiation time, min

Fig. 3 Effect of UV irradiation time on mutagenicity intensity $\left(\mathrm{MI}_{500}\right)$ of 3-methyl-4-nitrophenol solutions before and after chlorination: AOP (white circles) and $\mathrm{AOP} / \mathrm{Cl}$ (black circles), without (-S9mix) and with (+S9mix) metabolic activation in the Ames assay. The chlorination duration was $24 \mathrm{~h}$ for all experiments. $\mathrm{MI}_{500}$ is defined as mutagenicity intensity $(\mathrm{MI}=$ $\left(n-n_{0}\right) / n_{0}$, where $n$ is the number of His ${ }^{+}$revertants per plate, and $n$ is the number of spontaneous revertants per plate) at the dose of sample solution that had initially contained $500 \mu \mathrm{g}$ of 3-methyl-4-nitrophenol before AOP. Error bars indicate standard deviations of at least 2 measurements.

during AOP. The induced mutagenicity decreased with increasing AOP duration and had almost completely disappeared by $60 \mathrm{~min}$ of AOP, indicating that the mutagenic OTPs were transformed into nonmutagenic OTPs. The changes in mutagenicity of the 3M4NP solutions during $\mathrm{O}_{3}$ and AOP differed markedly: that is, no mutagenicity was induced by $\mathrm{O}_{3}$, whereas mutagenicity was induced by AOP. Whereas reaction with hydroxyl radicals is the major mechanism for decomposition during AOP (Andreozzi et al. 1999), both direct reaction with ozone and reaction with hydroxyl radicals are involved during $\mathrm{O}_{3}$ treatment (Hoigné and Bader 1976). This difference in reaction mechanism can be expected to result in the formation of different TPs and thus in different trends in mutagenicity.

In the TA98 assay with metabolic activation (Fig. 3f) and in TA100 assays without and with metabolic activation (Fig. 3g,h, respectively), samples subjected to chlorination alone showed relatively high mutagenicity $(t=0)$, but the mutagenicity induced by chlorination decreased with increasing AOP duration. These results suggest that during AOP, precursors of mutagenic CTPs were transformed into OTPs that were not precursors of mutagenic CTPs. Overall, pretreatment by AOP effectively reduced the final mutagenicity induced by chlorination, and therefore use of such a procedure might reduce the risk of exposure to mutagenic TPs in finished drinking water.

\subsection{Mutagenicity derived from COTPs}

As described in sections 3.2 and 3.3, mutagenicity was induced when the $3 \mathrm{M} 4 \mathrm{NP}$ solutions were subjected to $\mathrm{O}_{3} / \mathrm{Cl}$, AOP, and $\mathrm{AOP} / \mathrm{Cl}$, whereas $\mathrm{O}_{3}$ did not induce mutagenicity. As described in the introduction, C5H2NBA is thought to be a major contributor to the mutagenicity observed after chlorination of $3 \mathrm{M} 4 \mathrm{NP}$ solutions (i.e., it is thought to be a mutagenic CTP) (Takanashi et al. 2012). In the present study, we focused 

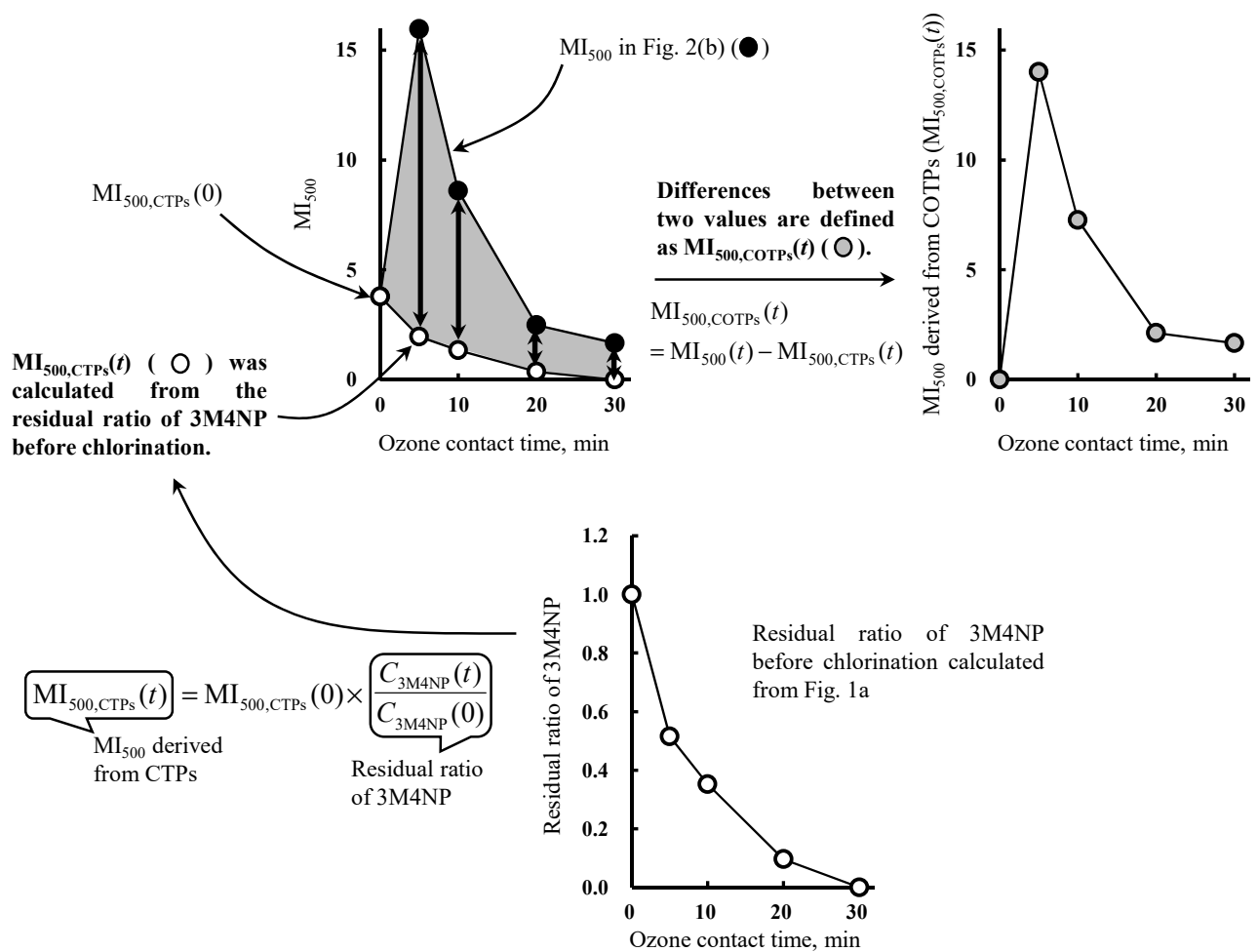
Fig. 4 Procedures for calculating $\mathrm{MI}_{500}$ derived from COTPs, $\mathrm{MI}_{500, \mathrm{COTPs}}(t)$, from observed $\mathrm{MI}_{500}$ values and 3-methyl-4-
nitrophenol (3M4NP) residual ratios. $\mathrm{MI}_{500}$ is defined as mutagenicity intensity $\left(\mathrm{MI}=\left(n-n_{0}\right) / n_{0}\right.$, where $n$ is the number of
$\mathrm{His}^{+}$revertants per plate, and $n$ is the number of spontaneous revertants per plate) at the dose of sample solution that had
initially contained $500 \mu \mathrm{g}$ of $3 \mathrm{M} 4 \mathrm{NP}$ before treatment. COTPs, transformation products generated during subsequent
chlorination after $\mathrm{O}_{3}$ and AOP; CTPs, transformation products by chlorination alone.

on elucidating possible contributors to the mutagenicity induced by oxidation processes other than chlorination, that is, $\mathrm{O}_{3} / \mathrm{Cl}$, AOP, and $\mathrm{AOP} / \mathrm{Cl}$, which produce OTPs (AOP) and COTPs $\left(\mathrm{O}_{3} / \mathrm{Cl}\right.$ and $\left.\mathrm{AOP} / \mathrm{Cl}\right)$. Before identifying such contributors, we excluded the contributions of CTPs to the mutagenicity induced by $\mathrm{O}_{3} / \mathrm{Cl}$ and $\mathrm{AOP} / \mathrm{Cl}$, as described below.

We reasoned that if we could quantify the mutagenicity per unit amount of $\mathrm{C} 5 \mathrm{H} 2 \mathrm{NBA}$ as measured by the Ames assay and if we could measure the concentration of $\mathrm{C} 5 \mathrm{H} 2 \mathrm{NBA}$ in crude samples withdrawn during $\mathrm{O}_{3} / \mathrm{Cl}$ and $\mathrm{AOP} / \mathrm{Cl}$, we could combine the mutagenicity and concentration data to determine the mutagenicity derived from $\mathrm{C} 5 \mathrm{H} 2 \mathrm{NBA}$ in the crude samples. However, because $\mathrm{C} 5 \mathrm{H} 2 \mathrm{NBA}$ is not commercially available, an Ames assay of C5H2NBA could not be conducted, and its concentration in the crude samples could not be measured. Moreover, CTPs other than
C5H2NBA may contribute to the mutagenicity of the chlorinated 3M4NP solution. Therefore, instead of attempting to measure the concentration and mutagenicity of $\mathrm{C} 5 \mathrm{H} 2 \mathrm{NBA}$, we estimated the contribution of total CTPs to the observed mutagenicity as follows (Fig. 4).

Because CTPs were directly generated by reaction of 3M4NP with chlorine, the concentrations of the mutagenic CTPs in the chlorinated $\mathrm{O}_{3}$ - and AOPtreated $3 \mathrm{M} 4 \mathrm{NP}$ solutions at a given $\mathrm{O}_{3}$ or AOP time $t$ could be assumed to be proportional to the concentration of residual $3 \mathrm{M} 4 \mathrm{NP}$ at time $t, C_{3 \mathrm{M} 4 \mathrm{NP}}(t)$. Accordingly, after chlorination, the mutagenicity derived from the mutagenic CTPs at time $t, \mathrm{MI}_{500, \mathrm{CTPs}}(t)$, is given by

$$
\mathrm{MI}_{500, \mathrm{CTPs}}(t)=\mathrm{MI}_{500, \mathrm{CTPs}}(0) \times \frac{C_{3 \mathrm{M} 4 \mathrm{NP}}(t)}{C_{3 \mathrm{M} 4 \mathrm{NP}}(0)}
$$


(a) TA98-S9mix, $\mathrm{O}_{3} / \mathrm{Cl}$

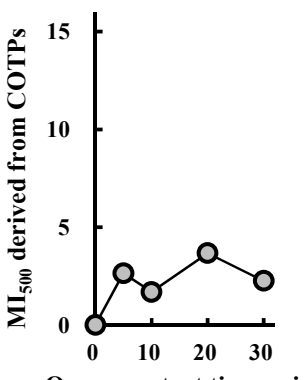

Ozone contact time, min

(e) TA98-S9mix, AOP/Cl

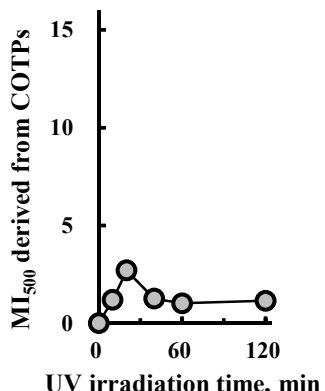

(b) TA98 +S9mix, $\mathrm{O}_{3} / \mathrm{Cl}$

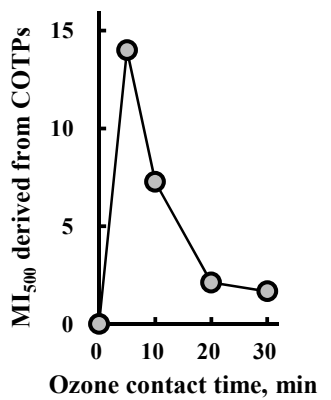

(f) TA98+S9mix, AOP/Cl

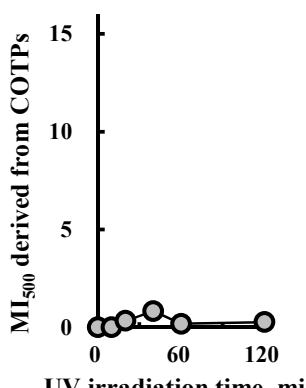

(c) TA100-S9mix, $\mathrm{O}_{3} / \mathrm{Cl}$

(d) TA100+S9mix, $\mathrm{O}_{3} / \mathrm{Cl}$

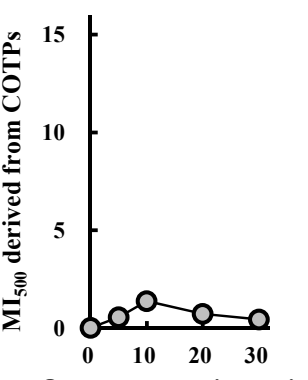

Ozone contact time, min

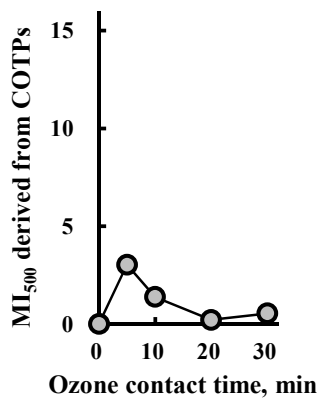

(g) TA100-S9mix, AOP/CI

(h) TA100 +S9mix, AOP/Cl
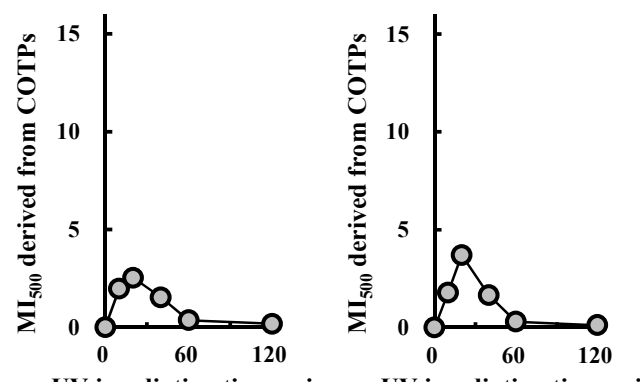

Fig. 5 Effects of $(a-d)$ ozone contact time during $\mathrm{O}_{3} / \mathrm{Cl}$ and $(\mathrm{e}-\mathrm{f}) \mathrm{UV}$ irradiation time during $\mathrm{AOP} / \mathrm{Cl}$ on mutagenicity intensity $\left(\mathrm{MI}_{500}\right)$ derived from COTPs, without $(-\mathrm{S} 9 \mathrm{mix})$ and with $(+\mathrm{S} 9 \mathrm{mix})$ metabolic activation in the Ames assay. The chlorination duration was $24 \mathrm{~h}$ for all experiments. $\mathrm{MI}_{500}$ is defined as mutagenicity intensity $\left(\mathrm{MI}=\left(n-n_{0}\right) / n_{0}\right.$, where $n$ is the number of $\mathrm{His}^{+}$revertants per plate, and $n$ is the number of spontaneous revertants per plate) at the dose of sample solution that had initially contained $500 \mu \mathrm{g}$ of 3-methyl-4-nitrophenol (3M4NP) before $\mathrm{O}_{3}$ or AOP. The $\mathrm{MI}_{500}$ values were modified by using the residual ratio of $3 \mathrm{M} 4 \mathrm{NP}$ before chlorination, on the assumption that the total mutagenicity exhibited by the reported chlorination-derived TPs was proportional to the concentration of residual 3M4NP before chlorination.

where $\mathrm{MI}_{500, \mathrm{CTPs}}(0)$ is the CTP-derived mutagenicity after chlorination at $t=0$, and $C_{3 \mathrm{M} 4 \mathrm{NP}}(0)$ is the initial 3 M4NP concentration before chlorination at $t=0$. We calculated the mutagenicity derived from mutagenic COTPs, MI500,COTPs $(t)$, which was the main target of the present study, by subtracting the CTP-derived mutagenicity from the observed mutagenicity, $\mathrm{MI}_{500}(t)$ :

$$
\mathrm{MI}_{500, \text { COTPs }}(t)=\mathrm{MI}_{500}(t)-\mathrm{MI}_{500, \mathrm{CTPs}}(t)
$$

The COTP-derived mutagenicity data calculated by means of this procedure are shown in Fig. 5. As described in sections 3.5 and 3.6, we then identified the possible contributors to the mutagenicity by using the datasets whose maximum $\mathrm{MI}_{500}$ was larger than 5 (shown in Fig. 3 for AOP, and in Fig. 5 for $\mathrm{O}_{3} / \mathrm{Cl}$ and $\mathrm{AOP} / \mathrm{Cl}$ ): the selected datasets were TA98 -S9mix for AOP, TA98 +S9mix for $\mathrm{O}_{3} / \mathrm{Cl}$, and TA100 -S9mix for AOP.

\subsection{Identification of OTPs and COTPs that contributed} to observed mutagenicities

To investigate the TPs generated during $\mathrm{O}_{3}, \mathrm{O}_{3} / \mathrm{Cl}$, AOP, and $\mathrm{AOP} / \mathrm{Cl}$, we performed LC/MS analysis on samples periodically withdrawn during the oxidation treatments. We detected a total of 138 peaks with maximum peak areas $\left(\mathrm{M}_{\mathrm{PA}}\right)$ of $>1 / 1,000$ the area of the peak for the initially added 3M4NP (i.e., before any treatments) (Table S1); among these peaks were 2 peaks with $\mathrm{M}_{\mathrm{PA}}$ values of $>1,7$ peaks with $\mathrm{M}_{\mathrm{PA}}$ values ranging from $1 / 10$ to 1 , and 36 peaks with $M_{P A}$ values ranging from $1 / 100$ to $1 / 10$.

To determine whether the TPs corresponding to any of these peaks contributed to the mutagenicity, we assumed that if a TP was strongly mutagenic, the trend of the mutagenicity of the 3M4NP solution after the oxidation treatments would be similar to the trend of the concentration of that TP. On the basis of this 
Table 1 Chemical structures of transformation products suspected of contributing to observed mutagenicity, along with mutagenicities predicted by quantitative structure-activity models.

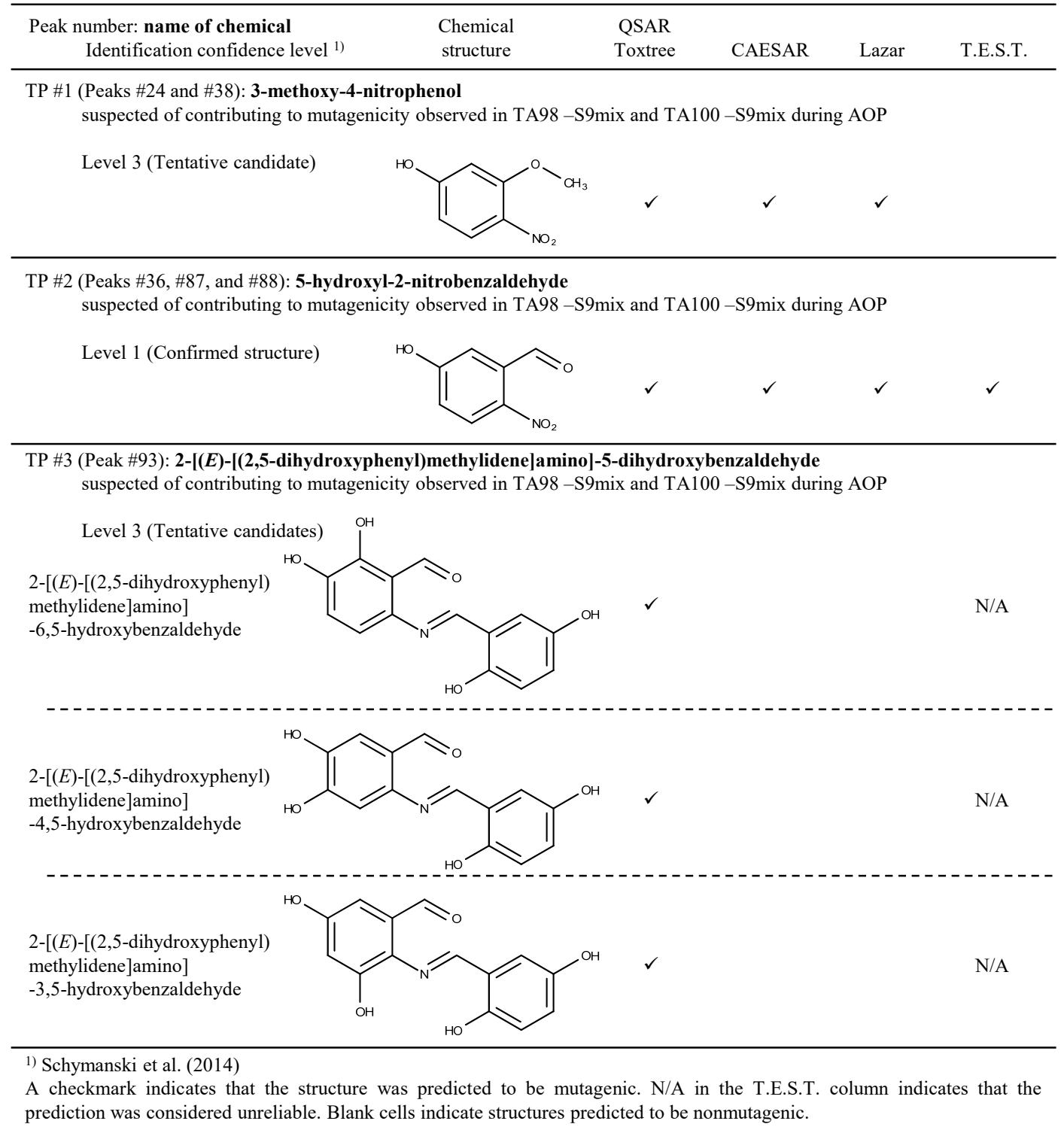

assumption, we performed simple regression analyses of the correlation between the $\mathrm{MI}_{500}$ of the treated 3M4NP solution and the peak area of each TP. Before the regression analyses, we modified the peak areas of the TPs for $\mathrm{O}_{3} / \mathrm{Cl}$ and $\mathrm{AOP} / \mathrm{Cl}$ by the residual $3 \mathrm{M} 4 \mathrm{NP}$ concentration according to the method used to calculate the COTP-derived mutagenicity (section 3.4), because CTPs were not the focus of the present study. The regression lines were constrained to pass through the origin. Coefficients of determination for the regression analyses are shown in Table S1. The areas of most of the peaks were not strongly correlated with mutagenicity, but the areas of 10 peaks (Peaks \#24, \#36,
\#38, \#56, \#65, \#66, \#74, \#87, \#88, and \#93) did show strong positive correlation $\left(r^{2} \geq 0.8\right)$ with mutagenicity. These results suggest that the TPs corresponding to these peaks may have contributed to the observed mutagenicity. The fact that none of these peaks were detected in the samples obtained after $\mathrm{O}_{3}$ (which induced no mutagenicity) is consistent with our assumption. For the sample AOP, Peak \#56 showed strong correlation $\left(r^{2}=0.98\right)$ with mutagenicity in the TA98 assay without metabolic activation, but for the $\mathrm{AOP} / \mathrm{Cl}$ sample, no strong mutagenicity was observed (Fig. 5e), even though the peak area for the $\mathrm{AOP} / \mathrm{Cl}$ sample $\left(\mathrm{M}_{\mathrm{PA}}=0.015\right)$ was greater than that for the AOP 
sample $\left(\mathrm{M}_{\mathrm{PA}}=0.003\right)$. This discrepancy strongly suggests that the TP corresponding to Peak \#56 did not contribute to the observed mutagenicity, so we eliminated it from the list of candidate mutagens. Similarly, we also eliminated any other peak whose area strongly correlated $\left(r^{2} \geq 0.8\right)$ with mutagenicity under a given Ames assay condition for a particular oxidation treatment but mutagenicity was not observed under the same Ames assay condition for any other oxidation treatment for which the peak was detected. In this way, Peaks \#65, and \#74 were also omitted from the candidate list, leaving 7 peaks on the list (Peaks \#24, \#36, \#38, \#66, \#87, \#88, and \#93).

On the basis of accurate $m / z$ values and MS/MS spectra of the 7 peaks, we determined the chemical structures of the TPs corresponding to these peaks (Table 1; the details of the procedure use to determine the structures are described in the SI). Peaks \#24 and \#38 were assumed to be the same TP (3-methoxy-4-nitrophenol, TP \#1), even though the compounds corresponding to these peaks must actually be different because their LC retention times were different; this limitation arises from the use of MS/MS spectra alone for identification. Peaks \#36, \#87, and \#88, which were detected in negative-ion mode, in negative-ion mode after derivatization, and in positive-ion mode after derivatization, respectively, were also determined to correspond to a single TP (5-hydroxy-2nitrobenzaldehyde, TP \#2). Peak \#93 was determined to be 2-[(E)-[(2,5-dihydroxyphenyl)methylidene $]$ amino]-5-dihydroxybenzaldehyde (TP \#3). TP \#3 consisted of 3 isomers that could not be distinguished solely by MS/MS analysis. Peak \#66 was determined to be chloro-3-(chloromethyl)-4-nitrophenol; Peak \#65, which had been eliminated from the candidate list according to the procedure described above, was also assigned to this compound. Accordingly, the TP corresponding to Peak \#66 was determined not to contribute to the observed mutagenicity. Therefore, after MS/MS analysis, 3 TPs (TP \#1-3) remained as candidate mutagens. The procedure for selecting the candidate mutagens is illustrated in Fig. 6.

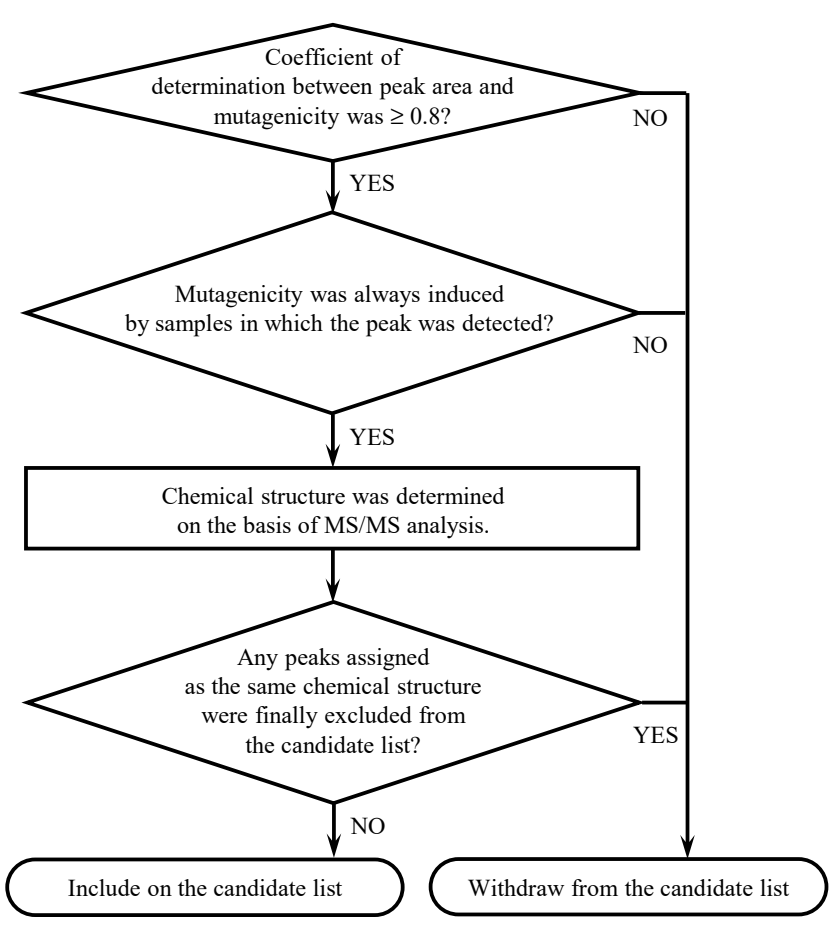

Fig. 6 Flowchart of selecting candidate TPs.

3.6 Prediction of mutagenicity of candidate TPs by QSAR analyses

To predict whether TPs \#1-3 showed Salmonella mutagenicity, we used 4 different QSAR models (Table 1) because the European Chemicals Agency recommends the use of at least 3 different models to avoid false-negative results (ECHA 2008). All 3 of the candidate TPs were predicted to be mutagenic by at least one of the models, indicating that these TPs could not be excluded from the list of candidate compounds suspected to contribute to the observed mutagenicity.

To clarify whether these TPs were in fact mutagenic, we would need to subject them to the Ames assay, but because we could not have found vendors dealing with TPs \#1 and \#3, we did not assay their mutagenicity. However, TP \#2 was commercially available, so we subjected it to Ames assays by using tester strains TA98 
and TA100 without metabolic activation. No mutagenicity was observed for either strain at concentrations up to $125 \mu \mathrm{g} / \mathrm{plate}$ (Fig. 7). The highest concentration of TP \#2 detected during the AOP experiment was $0.052 \mathrm{mg} / \mathrm{L}$ (Fig. 8), which corresponded to approximately $0.6 \%$ of the initially added 3M4NP. Because we expressed the mutagenicities of the AOP-treated samples in terms of $\mathrm{MI}_{500}$ values, defined as the $\mathrm{MI}$ at the dose of sample solution that initially contained $500 \mu \mathrm{g} /$ plate of $3 \mathrm{M} 4 \mathrm{NP}$ before any treatment, the highest concentration of TP \#2 corresponded to a dose of only approximately $3 \mu \mathrm{g}$ $(500 \times 0.6 / 100)$. Therefore, the amount of TP \#2 contained in the sample did not contribute to the mutagenicity observed in the AOP-treated samples. This left TPs \#1 (3-methoxy-4-nitrophenol) and \#3 (2[(E)-[(2,5-dihydroxyphenyl)methylidene]amino]-5dihydroxybenzaldehyde) as possible contributors to the mutagenicity of the 3M4NP solution after AOP. However, these TPs must be purchased or synthesized and subjected to the Ames assay, before they can be conclusively determined to have contributed to the observed mutagenicity. We were unable to determine compounds that contributed to the mutagenicity of the $3 \mathrm{M} 4 \mathrm{NP}$ solution after $\mathrm{O}_{3} / \mathrm{Cl}$ and $\mathrm{AOP} / \mathrm{Cl}$ in the present study.

In general, the oxidation of a given compound will generate many TPs. Conclusive determination of which TPs that contribute to mutagenicity induced by oxidation requires that Ames assays be carried out on an authentic sample of each TP. However, most TPs are unlikely to be commercially available and thus must be synthesized, which is time-consuming and expensive. The procedure described herein - that is, a combination of regression analysis, MS/MS analysis, and QSAR analysis - could be used to determine which TPs should be prioritized for further study (synthesis and Ames assay) and thus might save time and expense. (a) TA98-S9mix

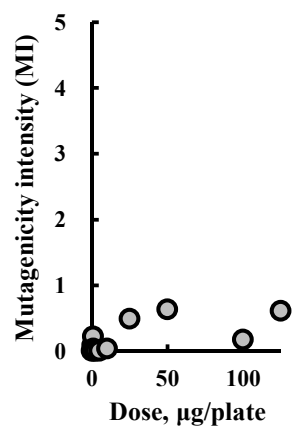

(b) TA100-S9mix

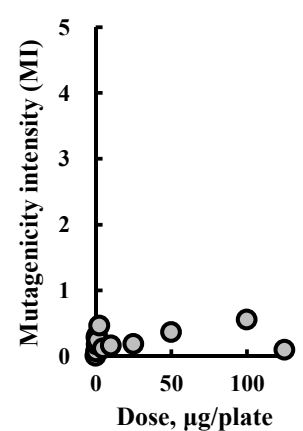

Fig. 7 Results of Ames mutagenicity assays of an authentic sample of 5-hydroxy-2-nitrobenzaldehyde (transformation product \#2; assigned to Peaks \#36, \#87, and \#88). $\mathrm{MI}=\left(n-n_{0}\right) / n_{0}$, where $n$ is the number of $\mathrm{His}^{+}$ revertants per plate and $n_{0}$ is the number of spontaneous revertants per plate. $-\mathrm{S} 9 \mathrm{mix}$, without metabolic activation.

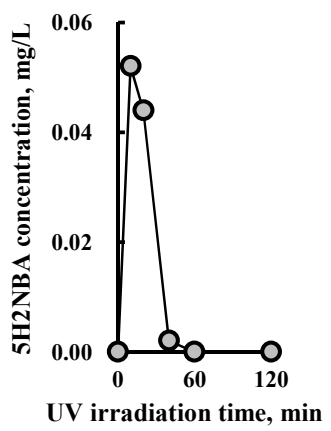

Fig. 8 Change in concentration of 5hydroxy-2-nitrobenzaldehyde (5H2NBA; transformation product $\# 2$; assigned to Peaks \#36, \#87, and \#88) during AOP.

\section{Conclusions}

1. Solutions of $3 \mathrm{M} 4 \mathrm{NP}$ were decomposed both by $\mathrm{O}_{3}$ and by AOP.

2. During AOP, the mutagenicity of the 3M4NP solution initially increased but then decreased with increasing UV irradiation time, finally dropping almost to zero. In contrast, no mutagenicity was induced by $\mathrm{O}_{3}$.

3. Although the mutagenicity induced by chlorination of the 3M4NP solution was increased by prior short-duration $\mathrm{O}_{3}$ or AOP, increasing the duration of $\mathrm{O}_{3}$ or AOP decreased the mutagenicity induced by subsequent chlorination: that is, both $\mathrm{O}_{3}$ and AOP effectively reduced the final mutagenicity of 3M4NP solutions after chlorination.

4. By using regression analyses of correlations 
between TP peak area and observed mutagenicity, and subsequent MS/MS analysis, we identified 3 TPs (TPs \#1-3) suspected of contributing to the observed mutagenicity.

5. Four different QSAR models were applied to TPS \#1-3, and all 3 TPs were predicted to be mutagenic by at least one of the models, suggesting that these TPs contributed to the observed mutagenicity.

6. However, an Ames assay on an authentic sample of TP \#2 revealed that it did not contribute to the mutagenicity.

7. Two TPs, 3-methoxy-4-nitrophenol (TP \#1) and 2[(E)-[(2,5-dihydroxy phenyl)methylidene]amino]5-hydroxybenzaldehyde (TP \#3), remained on the list of compounds suspected of contributing to the mutagenicity induced by AOP. We were unable to identify the TPs that contributed to the mutagenicities of $\mathrm{O}_{3} / \mathrm{Cl}$ and $\mathrm{AOP} / \mathrm{Cl}$ in the present study.

8. The procedure described herein - that is, a combination of regression analysis, MS/MS analysis, and QSAR analysis - may be useful for prioritizing TPs for further study (i.e., synthesis and Ames assay).

\section{Acknowledgments}

This research was supported in part by a Grant-in-Aid for Scientific Research S (16H06362) from the Japan Society for the Promotion of Science and by the Environment Research and Technology Development Fund (5B-1104) of the Ministry of the Environment, Japan.

\section{References}

Adhya, T.K., Sudhakar, B. and Sethunathan, N. (1981) Stability of commercial formulation of fenitrothion, methyl parathion, and parathion in anaerobic soils. Journal of Agricultural and Food Chemistry 29(1), 90-93.
Andreozzi, R., Caprio, V., Insola, A. and Marotta, R. (1999) Advanced oxidation processes (AOP) for water purification and recovery. Catalysis Today 53(1), 51-59.

ECHA (2008) Guidance on Information Requirements and Chemical Safety Assessment Chapter R.7a: Endpoint Specific Guidance.

Escher, B.I. and Fenner, K. (2011) Recent Advances in Environmental Risk Assessment of Transformation Products. Environmental Science \& Technology 45(9), 3835-3847.

Fenner, K., Canonica, S., Wackett, L.P. and Elsner, M. (2013) Evaluating pesticide degradation in the environment: blind spots and emerging opportunities. Science 341(6147), 752-758.

Hala, D., Overturf, M.D., Petersen, L.H. and Huggett, D.B. (2011) Quantification of 2-hydrazinopyridine derivatized steroid hormones in fathead minnow (Pimephales promelas) blood plasma using LCESI+/MS/MS. Journal of Chromatography B 879(910), 591-598.

Hansen, K., Mika, S., Schroeter, T., Sutter, A., ter Laak, A., Steger-Hartmann, T., Heinrich, N. and Müller, K.-R. (2009) Benchmark data set for in silico prediction of Ames mutagenicity. Journal of Chemical Information and Modeling 49(9), 2077 2081 .

Hara, M., Kogiso, S., Yamada, F., Kawamoto, M., Yoshitake, A. and Miyamoto, J. (1989) Mutagenicity studies on fenitrothion in bacteria and mammalian cells. Mutation Research/Genetic Toxicology 222(1), 53-61.

Higashi, T., Shibayama, Y., Ichikawa, T., Ito, K., Toyo’oka, T., Shimada, K., Mitamura, K., Ikegawa, S. and Chiba, H. (2010) Salivary chenodeoxycholic acid and its glycine-conjugate: Their determination method using LC-MS/MS and variation of their concentrations with increased saliva flow rate. Steroids 75(4-5), 338-345. 
Hoigné, J. and Bader, H. (1976) The role of hydroxyl radical reactions in ozonation processes in aqueous solutions. Water Res 10(5), 377-386.

Kameya, T., Saito, M., Kondo, T., Toriumi, W., Fujie, K., Matsushita, T. and Takanashi, H. (2012) Detection of fenitrothion and its degradation product 3-methyl-4-nitrophenol in water environment. Journal of Water and Environment Technology $10(4), 427-436$.

Kazius, J., McGuire, R. and Bursi, R. (2005) Derivation and validation of toxicophores for mutagenicity prediction. Journal of Medicinal Chemistry 48(1), 312-320.

Kishida, M., Kumabe, T., Takanashi, H., Nakajima, T., Ohki, A., Miyake, Y. and Kameya, T. (2010) Chlorination by-products of fenitrothion. Water Science and Technology 62(1), 85-91.

Koga, M., Kadokami, K. and Shinohara, R. (1992) Laboratory-scale ozonation of water contaminated with trace pesticides. Water Science and Technology 26(9-11), 2257-2260.

Kormali, P., Dimoticali, D., Tsipi, D., Hiskia, A. and Papaconstantinou, E. (2004) Photolytic and photocatalytic decomposition of fenitrothion by PW12O403- and TiO2: a comparative study. Applied Catalysis B: Environmental 48(3), 175-183. Maron, D.M. and Ames, B.N. (1983) Revised methods for the Salmonella mutagenicity test. Mutation Research/Environmental Mutagenesis and Related Subjects 113(3), 173-215.

Matsushita, T., Matsui, Y. and Matsui, Y. (2006) Estimating mutagenic compounds generated during photolysis of fenitrothion-by HPLC fractionation followed by mutagenicity testing and highresolution GC-MS analysis. Chemosphere 64(1), 144-151.

Mikami, N., Imanishi, K., Yamada, H. and Miyamoto, J. (1985a) Photodegradation of fenitrothion in water and on soil surface, and its hydrolysis in water.
Journal of Pesticide Science 10, 263-272.

Mikami, N., Sakata, S., Yamada, H. and Miyamoto, J. (1985b) Further studies on degradation of fenitrothion in soils. Journal of Pesticide Science 10, 491-500.

Misra, D., Sreedharan, B., Bhuyan, S. and Sethunathan, N. (1993) Accelerated degradation of fenitrothion in fenitrothion- or 3 methyl-4-nitrophenolacclimatized soil suspensions. Chemosphere 27(8), 1529-1538.

Miyamoto, J., Mikami, N., Mihara, K., Takimoto, Y., Kohda, H. and Suzuki, H. (1978) Biological activity of fenitrothion and its degradation products. Journal of Pesticide Science 3(1), 35-41.

Ohkawa, H., Mikami, N. and Miyamoto, J. (1974) Photodecomposition of Sumithion ${ }^{\circledR} \quad[\mathrm{O}, \mathrm{O}-$ Dimethyl-O-(3-methyl-4-nitrophenyl)phosphorothioate]. Agricultural and Biological Chemistry 38(11), 2247-2255.

Park, J.H., Lee, B.J., Lee, S.K., Kim, K., Lee, K.H., Che, J.H., Kang, K.S. and Lee, Y.S. (2000) Genotoxicity of drinking water from three Korean cities. Mutation Research/Genetic Toxicology and Environmental Mutagenesis 466, 173-178.

Schymanski, E.L., Jeon, J., Gulde, R., Fenner, K., Ruff, M., Singer, H.P. and Hollender, J. (2014) Identifying small molecules via high resolution mass spectrometry: communicating confidence. Environmental Science \& Technology 48, 20972098.

Sinclair, C.J., Boxall, A.B.A., Parsons, S.A. and Thomas, M.R. (2006) Prioritization of Pesticide Environmental Transformation Products in Drinking Water Supplies. Environmental Science \& Technology 40(23), 7283-7289.

Spillner, C.J., DeBaun, J.R. and Menn, J.J. (1979) Degradation of fenitrothion in forest soil and effects on forest soil microbes. Journal of Agricultural and Food Chemistry 27(5), 1054-1060. 
Takanashi, H., Kishida, M., Nakajima, T., Ohki, A., Akiba, M. and Aizawa, T. (2009) Surveying the mutagenicity of tap water to elicit the effects of purification processes on Japanese tap water. Chemosphere 77, 434-439.

Takanashi, H., Abiru, K., Tanaka, H., Kishida, M., Nakajima, T., Ohki, A., Kondo, T., Kameya, T. and Matsushita, T. (2012) Production of chloro-5hydroxy-2-nitrobenzoic acid through chlorination of 3-methyl-4-nitrophenol, a typical hydrolysate of fenitrothion. Journal of Water and Environment Technology 10(4), 437-447.

Takanashi, H., Hama, T., Nakajima, T., Ohki, A., Kondo, T., Kameya, T. and Matsushita, T. (2014) A Screening study of mutagen formation potential (MFP) of pesticide transformation products in water environments (PTPWs) to investigate the MFP changes from their parent pesticides through transformations. Journal of Water and Environment Technology 12(1), 25-32.

Takimoto, Y., Hirota, M., Inui, H. and Miyamoto, J. (1976) Decomposition and leaching of radioactive Sumithion in 4 different soils under laboratory conditions. Journal of Pesticide Science 1, 131-143. Vartiainen, T. and Liimatainen, A. (1986) High levels of mutagenic activity in chlorinated drinking water in Finland. Mutation Research/Genetic Toxicology 169, 29-34.

Zeiger, E. (1987) Carcinogenicity of mutagens: predictive capability of the Salmonella mutagenesis assay for rodent carcinogenicity. Cancer Research 47(5), 1287-1296. 


\section{Supplementary information}

Identification of mutagenic transformation products generated during oxidation of 3-methyl4-nitrophenol solutions by orbitrap tandem mass spectrometry and quantitative structureactivity relationship analyses

Taku Matsushita $^{1^{*}}$, Shiho Honda², Taisuke Kuriyama², Yuki Fujita ${ }^{2}$, Takashi Kondo², Yoshihiko Matsui $^{1}$, Nobutaka Shirasaki ${ }^{1}$, Hirokazu Takanashi ${ }^{3}$ and Takashi Kameya ${ }^{4}$

${ }^{1}$ Faculty of Engineering, Hokkaido University, N13W8, Sapporo 060-8628, Japan

${ }^{2}$ Graduate School of Engineering, Hokkaido University, N13W8, Sapporo 060-8628, Japan

${ }^{3}$ Faculty of Science and Engineering, Kagoshima University, 1-21-40 Korimoto, Kagoshima 890-0065, Japan

${ }^{4}$ Faculty of Environment and Information Sciences, Yokohama National University, 79-7 Tokiwadai, Hodogaya, Yokohama 240-8501, Japan

${ }^{*}$ Corresponding author: taku-m@eng.hokudai.ac.jp, +81-11-706-7279

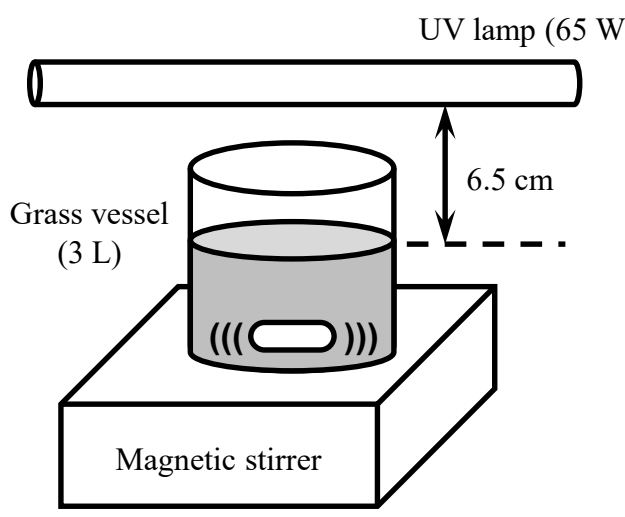

Fig. S1 Configuration of AOP reactor. 
Table S1 Coefficients of determination for the relationship between relative concentrations of the detected transformation products (TPs), that is, (peak area of TP)/(peak area of 3 methyl-4-nitrophenol initially contained in sample solution before treatment), and mutagenicity intensity $\left(\mathrm{MI}_{500}\right)$ after each treatment process. $\mathrm{MI}_{500}$ is defined as $\mathrm{MI}\left(=\left(n-n_{0}\right) / n_{0}\right.$ where $n$ is the number of $\mathrm{His}^{+}$revertants per plate, and $n$ is the number of spontaneous revertants per plate) at the dose of sample solution that initially contained $500 \mu \mathrm{g}$ of $3-$ methyl-4-nitrophenol before treatment. Regression lines were constrained to pass through the origin. Transformation products for which $r^{2}$ was $>0.8$ are highlighted in gray. Abbreviations: $\mathrm{p}$, positive-ion mode; $\mathrm{p}$-d, positive-ion mode with derivatization; n, negative-ion mode; $\mathrm{n}-\mathrm{d}$, negative-ion mode with derivatization; -S9mix and +S9mix, without and with metabolic activation in the Ames assay, respectively.

\begin{tabular}{|c|c|c|c|c|c|c|c|c|c|c|c|c|c|c|c|c|c|c|c|}
\hline & & & & & & & & & & & & & ient of & erminat & $\left(r^{2}\right)$ & & & & \\
\hline \# & $\mathrm{m} / \mathrm{z}$ & $\begin{array}{l}\text { Retention } \\
\text { time. }\end{array}$ & Ion & & lative co & centrati & & & TAS & 99 mix & & & TA98 & 9 mix & & & TA1C & S9 mix & \\
\hline & & & mode & $\mathrm{O}_{3}$ & $\begin{array}{l}\mathrm{O}_{3} \\
/ \mathrm{Cl}\end{array}$ & $\mathrm{AOP}$ & $\begin{array}{c}\mathrm{AOP} \\
/ \mathrm{Cl}\end{array}$ & $\mathrm{O}_{3}$ & $\begin{array}{l}\mathrm{O}_{3} \\
/ \mathrm{Cl} \\
\end{array}$ & $\mathrm{AOP}$ & $\begin{array}{c}\mathrm{AOP} \\
/ \mathrm{Cl}\end{array}$ & $\mathrm{O}_{3}$ & $\begin{array}{l}\mathrm{O}_{3} \\
/ \mathrm{Cl}\end{array}$ & $\mathrm{AOP}$ & $\begin{array}{c}\mathrm{AOP} \\
/ \mathrm{Cl}\end{array}$ & $\mathrm{O}_{3}$ & $\begin{array}{l}\mathrm{O}_{3} \\
/ \mathrm{Cl}\end{array}$ & $\mathrm{AOP}$ & $\begin{array}{c}\mathrm{AOP} \\
/ \mathrm{Cl}\end{array}$ \\
\hline 1 & 59.0491 & 1.1 & $\mathrm{p}$ & 0.006 & 0.004 & 0.002 & & - & 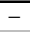 & -0.02 & 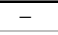 & 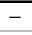 & -0.64 & - & - & - & - & -0.02 & - \\
\hline 2 & 59.0493 & 1.3 & $\mathrm{p}$ & & & 0.002 & & - & - & -0.02 & - & - & & - & - & - & - & -0.02 & - \\
\hline 3 & 73.0648 & 8.2 & $\mathrm{p}$ & & 0.008 & & & - & - & & - & - & -0.33 & - & - & - & - & & - \\
\hline 4 & 73.0650 & 8.5 & $\mathrm{p}-\mathrm{d}$ & & & 0.148 & & - & - & -0.06 & - & - & & - & - & - & - & -0.06 & - \\
\hline 5 & 90.9768 & 1.0 & $\mathrm{p}$ & & & 0.003 & & - & - & -0.03 & - & - & & - & - & - & - & -0.03 & - \\
\hline 6 & 94.0523 & 7.7 & $\mathrm{p}-\mathrm{d}$ & & & & 0.006 & - & - & & - & - & & - & - & - & - & & - \\
\hline 7 & 94.0523 & 8.2 & $\mathrm{p}-\mathrm{d}$ & & & & 0.030 & - & - & & - & - & & - & - & - & - & & - \\
\hline 8 & 94.0523 & 9.0 & $p-d$ & & & & 0.015 & - & - & & - & - & & - & - & - & - & & - \\
\hline 9 & 96.9590 & 1.0 & $\mathrm{n}-\mathrm{d}$ & & & 0.028 & & - & - & -0.16 & - & - & & - & - & - & - & -0.19 & - \\
\hline 10 & 96.9591 & 0.8 & $\mathrm{n}$ & & 0.006 & 0.026 & 0.013 & - & - & 0.00 & - & - & -0.80 & - & - & - & - & 0.00 & - \\
\hline 11 & 98.9548 & 1.0 & $\mathrm{n}$ & & & 0.002 & & - & - & -0.04 & - & - & & - & - & - & - & -0.03 & - \\
\hline 12 & 108.0558 & 8.0 & p-d & & & & 0.022 & - & - & & - & - & & - & - & - & - & & - \\
\hline 13 & 112.9847 & 0.9 & $\mathrm{n}$ & 0.004 & 0.010 & 0.011 & 0.008 & - & - & -0.01 & - & - & -0.26 & - & - & - & - & 0.00 & - \\
\hline 14 & 112.9847 & 1.1 & $\mathrm{n}-\mathrm{d}$ & & & 0.012 & & - & - & -0.16 & - & - & & - & - & - & - & -0.02 & - \\
\hline 15 & 120.0558 & 8.8 & p-d & 0.005 & & & 0.014 & - & - & & - & - & & - & - & - & - & & - \\
\hline 16 & 122.0365 & 8.5 & $\mathrm{n}$ & 0.008 & & 0.009 & & - & - & -0.35 & - & - & & - & - & - & - & -0.47 & - \\
\hline 17 & 122.0366 & 8.5 & $\mathrm{n}-\mathrm{d}$ & 0.004 & & 0.004 & & - & - & -0.39 & - & - & & - & - & - & - & -0.52 & - \\
\hline 18 & 122.0714 & 7.7 & $\mathrm{p}-\mathrm{d}$ & 0.021 & 0.020 & 0.024 & 0.422 & - & - & 0.10 & - & - & 0.06 & - & - & - & - & 0.11 & - \\
\hline 19 & 128.9536 & 1.0 & $\mathrm{p}$ & & & 0.003 & & - & - & -0.03 & - & - & & - & - & - & - & -0.03 & - \\
\hline 20 & 132.8672 & 8.4 & n-d & & & 0.001 & & - & - & 0.01 & - & - & & - & - & - & - & 0.01 & - \\
\hline 21 & 133.0763 & 8.2 & $\mathrm{p}-\mathrm{d}$ & & & & 0.060 & - & - & & - & - & & - & - & - & - & & - \\
\hline 22 & 134.8647 & 8.4 & $\mathrm{n}-\mathrm{d}$ & & & 0.001 & & - & - & -0.09 & - & - & & - & - & - & - & -0.10 & - \\
\hline 23 & 136.0871 & 8.0 & $\mathrm{p}-\mathrm{d}$ & 0.009 & 0.008 & & 0.078 & - & - & & - & - & -0.06 & - & - & - & - & & - \\
\hline 24 & 138.0316 & 8.8 & $\mathrm{n}$ & & & 0.001 & & - & - & 0.98 & - & - & & - & - & - & - & 0.95 & - \\
\hline 25 & 140.9510 & 1.1 & $\mathrm{n}$ & & 0.001 & & 0.002 & - & - & & - & - & 0.55 & - & - & - & - & & - \\
\hline 26 & 147.0918 & 9.1 & $\mathrm{p}-\mathrm{d}$ & 0.005 & 0.004 & 0.009 & 0.034 & - & - & 0.06 & - & - & -0.11 & - & - & - & - & 0.07 & - \\
\hline 27 & 149.0235 & 13.4 & $\mathrm{p}$ & & & 0.011 & & - & - & 0.02 & - & - & & - & - & - & - & 0.02 & - \\
\hline 28 & 149.0235 & 13.4 & $\mathrm{p}-\mathrm{d}$ & & & 0.006 & & - & - & -0.01 & - & - & & - & - & - & - & -0.02 & - \\
\hline 29 & 150.1027 & 8.2 & $\mathrm{p}-\mathrm{d}$ & 0.054 & 0.043 & 0.029 & 3.197 & - & - & 0.17 & - & - & 0.04 & - & - & - & - & 0.19 & - \\
\hline 30 & 152.0345 & 8.5 & $\mathrm{n}-\mathrm{d}$ & & & 0.648 & & - & - & -0.39 & - & - & & - & - & - & - & -0.52 & - \\
\hline 31 & 157.0762 & 8.5 & $\mathrm{p}-\mathrm{d}$ & 0.010 & 0.005 & 0.153 & 0.192 & - & - & 0.12 & - & - & -0.31 & - & - & - & - & 0.13 & - \\
\hline 32 & 158.1541 & 9.9 & $\mathrm{p}$ & 0.001 & & 0.002 & & - & - & 0.02 & - & - & & - & - & - & - & 0.02 & - \\
\hline 33 & 163.1331 & 8.5 & $\mathrm{p}$ & & & 0.003 & & - & - & -0.02 & - & - & & - & - & - & - & -0.02 & - \\
\hline 34 & 164.1183 & 9.1 & $\mathrm{p}-\mathrm{d}$ & 0.172 & 0.137 & 0.227 & 2.273 & - & - & 0.10 & - & - & -0.13 & - & - & - & - & 0.12 & - \\
\hline 35 & 164.9206 & 1.0 & $\mathrm{p}$ & & & 0.002 & & - & - & -0.07 & - & - & & - & - & - & - & -0.07 & - \\
\hline 36 & 166.0141 & 7.7 & $\mathrm{n}$ & & & 0.007 & & - & - & 0.99 & - & - & & - & - & - & - & 0.97 & - \\
\hline 37 & 166.9984 & 8.5 & $\mathrm{n}$ & & 0.004 & & 0.002 & - & - & & - & - & 0.54 & - & - & - & - & & - \\
\hline 38 & 168.0298 & 7.3 & $\mathrm{n}$ & & & 0.002 & & - & - & 1.00 & - & - & & - & - & - & - & 0.97 & - \\
\hline 39 & 173.0712 & 7.2 & p-d & & & 0.005 & & - & - & -0.01 & - & - & & - & - & - & - & -0.01 & - \\
\hline 40 & 178.1340 & 10.1 & p-d & 0.010 & 0.009 & 0.030 & 0.224 & - & - & 0.22 & - & - & -0.67 & - & - & - & - & 0.25 & - \\
\hline 41 & 180.0767 & 7.5 & p-d & & & & 0.006 & - & - & & - & - & & - & - & - & - & & - \\
\hline 42 & 180.1132 & 7.9 & $\mathrm{p}-\mathrm{d}$ & & & & 0.005 & - & - & & - & - & & - & - & - & - & & - \\
\hline 43 & 180.1132 & 8.3 & p-d & & & & 0.001 & - & - & & - & - & & - & - & - & - & & - \\
\hline 44 & 181.0496 & 13.4 & $\mathrm{p}$ & & & 0.002 & & - & - & 0.06 & - & - & & - & - & - & - & 0.02 & - \\
\hline 45 & 182.0925 & 8.0 & p-d & & & & 0.024 & - & - & & - & - & & - & - & - & - & & - \\
\hline 46 & 185.0824 & 8.1 & p-d & & & 0.016 & 0.018 & - & - & -0.04 & - & - & & - & - & - & - & -0.05 & - \\
\hline 47 & 185.9960 & 8.7 & $\mathrm{n}$ & & & & 0.005 & - & - & & - & - & & - & - & - & - & & - \\
\hline 48 & 187.0980 & 8.2 & p-d & 0.024 & 0.094 & 0.066 & 0.101 & - & - & 0.14 & - & - & -0.87 & - & - & - & - & 0.15 & - \\
\hline 49 & 187.1265 & 8.8 & $\mathrm{p}$ & 0.001 & & 0.006 & & - & - & 0.01 & - & - & & - & - & - & - & 0.01 & - \\
\hline 50 & 187.9757 & 8.5 & $\mathrm{n}$ & & 0.002 & & & - & - & & - & - & 0.54 & - & - & - & - & & - \\
\hline 51 & 191.1642 & 9.6 & $\mathrm{p}$ & & & 0.001 & & - & - & 0.05 & - & - & & - & - & - & - & 0.05 & - \\
\hline 52 & 194.9270 & 0.9 & $\mathrm{n}$ & & & 0.007 & 0.003 & - & - & -0.04 & - & - & & - & - & - & - & -0.04 & - \\
\hline 53 & 194.9272 & 1.0 & n-d & & & 0.005 & & - & - & -0.28 & - & - & & - & - & - & - & -0.33 & - \\
\hline 54 & 197.0203 & 7.5 & $\mathrm{n}$ & 0.003 & 0.002 & 0.001 & & - & - & -0.37 & - & - & 0.01 & - & - & - & - & -0.49 & - \\
\hline 55 & 201.0771 & 7.9 & $\mathrm{p}-\mathrm{d}$ & & & & 0.011 & - & - & & - & - & & - & - & - & - & & - \\
\hline 56 & 204.0769 & 7.4 & p-d & & 0.005 & 0.003 & 0.015 & - & - & 0.98 & - & - & 0.84 & - & - & - & - & 0.97 & - \\
\hline 57 & 205.1437 & 9.2 & $\mathrm{p}$ & & & 0.003 & & - & - & 0.00 & - & - & & - & - & - & - & 0.00 & - \\
\hline 58 & 207.1594 & 8.6 & p & & & 0.002 & & - & - & -0.01 & - & - & & - & - & - & - & -0.01 & - \\
\hline 59 & 208.1445 & 8.5 & p-d & 0.001 & 0.002 & & 0.032 & - & - & & - & - & -0.83 & - & - & - & - & & - \\
\hline 60 & 215.1041 & 8.1 & p-d & & & & 0.013 & - & - & & - & - & & - & - & - & - & & - \\
\hline 61 & 216.9088 & 1.0 & $\mathrm{n}$ & & & 0.002 & & - & - & -0.04 & - & - & & - & - & - & - & -0.03 & - \\
\hline 62 & 216.9091 & 1.0 & n-d & & & 0.001 & & - & - & -0.40 & - & - & & - & - & - & - & -0.46 & - \\
\hline 63 & 217.0722 & 7.9 & p-d & & & & 0.015 & - & - & & - & - & & - & - & - & - & & - \\
\hline 64 & 219.0085 & 9.2 & p-d & & & & 0.005 & - & - & & - & - & & - & - & - & - & & - \\
\hline 65 & 219.9573 & 8.2 & $\mathrm{n}$ & & 0.100 & & 0.061 & - & - & & - & - & 0.89 & - & - & - & - & & - \\
\hline 66 & 219.9574 & 8.2 & n-d & & 0.036 & & & - & - & & - & - & 0.94 & - & - & - & - & & - \\
\hline 67 & 220.9414 & 8.3 & $\mathrm{n}$ & & 0.004 & & 0.001 & - & - & & - & - & 0.54 & - & - & - & - & & - \\
\hline 68 & 222.1702 & 9.2 & $\mathrm{p}$ & & & 0.002 & & - & - & -0.01 & - & - & & - & - & - & - & -0.01 & - \\
\hline 69 & 223.0638 & 10.4 & $\mathrm{p}$ & & & 0.002 & 0.026 & - & - & 0.02 & - & - & & - & - & - & - & 0.02 & - \\
\hline 70 & 226.9517 & 1.1 & $\mathrm{p}$ & & & 0.001 & & - & - & -0.06 & - & - & & - & - & - & - & -0.06 & - \\
\hline 71 & 227.1040 & 8.7 & $\mathrm{p}-\mathrm{d}$ & 0.005 & 0.002 & & 0.024 & - & - & & - & - & -0.76 & - & - & - & - & & - \\
\hline 72 & 229.0860 & 11.3 & p-d & & & 0.002 & & - & - & -0.04 & - & - & & - & - & - & - & -0.04 & - \\
\hline 73 & 229.0862 & 11.3 & $\mathrm{p}$ & & & 0.003 & & - & - & 0.01 & - & - & & - & - & - & - & 0.01 & - \\
\hline 74 & 230.9808 & 8.1 & $\mathrm{n}$ & & 0.007 & & 0.003 & - & - & & - & - & 0.86 & - & - & - & - & & - \\
\hline 75 & 233.9363 & 7.4 & $\mathrm{n}$ & & & & 0.005 & - & - & & - & - & & - & - & - & - & & - \\
\hline 76 & 236.1032 & 7.6 & $\mathrm{p}-\mathrm{d}$ & & & 0.002 & 0.007 & - & - & -0.24 & - & - & & - & - & - & - & -0.27 & - \\
\hline
\end{tabular}


Table S1 (Continued)

\begin{tabular}{|c|c|c|c|c|c|c|c|c|c|c|c|c|c|c|c|c|c|c|c|}
\hline \multirow{3}{*}{ \# } & \multirow{3}{*}{$m / z$} & \multirow{3}{*}{$\begin{array}{l}\text { Retention } \\
\text { time, } \\
\text { min }\end{array}$} & \multirow{3}{*}{$\begin{array}{l}\text { Ion } \\
\text { mode }\end{array}$} & \multirow{2}{*}{\multicolumn{4}{|c|}{$\begin{array}{c}\text { Maximum } \\
\text { relative concentration }\end{array}$}} & \multicolumn{12}{|c|}{ Coefficient of determination $\left(r^{2}\right)$} \\
\hline & & & & & & & & \multicolumn{4}{|c|}{ TA98 -S9 mix } & & TA98 & 9 mix & & & ГA 10 & S9 mix & \\
\hline & & & & $\mathrm{O}_{3}$ & $\begin{array}{l}\mathrm{O}_{3} \\
/ \mathrm{Cl} \\
\end{array}$ & $\mathrm{AOP}$ & $\begin{array}{c}\mathrm{AOP} \\
\mathrm{ACl} \\
\end{array}$ & $\mathrm{O}_{3}$ & $\begin{array}{l}\mathrm{O}_{3} \\
/ \mathrm{Cl} \\
\end{array}$ & $\mathrm{AOP}$ & $\begin{array}{c}\mathrm{AOP} \\
/ \mathrm{Cl}\end{array}$ & $\mathrm{O}_{3}$ & $\begin{array}{l}\mathrm{O}_{3} \\
/ \mathrm{Cl} \\
\end{array}$ & AOP & $\begin{array}{c}\mathrm{AOP} \\
/ \mathrm{Cl}\end{array}$ & $\mathrm{O}_{3}$ & $\begin{array}{l}\mathrm{O}_{3} \\
/ \mathrm{Cl} \\
\end{array}$ & $\mathrm{AOP}$ & $\begin{array}{r}\mathrm{AOP} \\
/ \mathrm{Cl} \\
\end{array}$ \\
\hline 77 & 238.0378 & 8.1 & p-d & & 0.003 & & 0.010 & - & - & & - & - & 0.54 & - & - & - & - & & - \\
\hline 78 & 240.0532 & 8.2 & p-d & & & & 0.009 & - & - & & - & - & & - & - & - & - & & - \\
\hline 79 & 241.0724 & 10.5 & $\mathrm{n}-\mathrm{d}$ & & 0.012 & & & - & - & & - & - & -0.90 & - & - & - & - & & - \\
\hline 80 & 241.1196 & 8.9 & $\mathrm{p}-\mathrm{d}$ & & 0.002 & & 0.017 & - & - & & - & - & 0.74 & - & - & - & - & & - \\
\hline 81 & 248.0799 & 11.0 & $\mathrm{n}-\mathrm{d}$ & & 0.005 & 0.001 & & - & - & -0.03 & - & - & -0.25 & - & - & - & - & -0.03 & - \\
\hline 82 & 249.2061 & 10.4 & $\mathrm{p}-\mathrm{d}$ & 0.001 & & 0.004 & 0.008 & - & - & 0.00 & - & - & & - & - & - & - & 0.00 & - \\
\hline 83 & 249.2061 & 10.4 & $\mathrm{p}$ & & & 0.013 & & - & - & 0.00 & - & - & & - & - & - & - & 0.00 & - \\
\hline 84 & 255.1353 & 9.5 & $\mathrm{p}-\mathrm{d}$ & & 0.003 & 0.003 & 0.014 & - & - & 0.77 & - & - & 0.80 & - & - & - & - & 0.75 & - \\
\hline 85 & 255.2327 & 17.3 & $\mathrm{n}$ & 0.007 & 0.018 & 0.011 & 0.009 & - & - & 0.04 & - & - & -0.13 & - & - & - & - & 0.04 & - \\
\hline 86 & 255.2326 & 17.2 & $\mathrm{n}-\mathrm{d}$ & & & 0.007 & & - & - & 0.08 & - & - & & - & - & - & - & 0.00 & - \\
\hline 87 & 257.0677 & 9.1 & $\mathrm{n}-\mathrm{d}$ & & & 0.003 & & - & - & 0.97 & - & - & & - & - & - & - & 0.94 & - \\
\hline 88 & 259.0826 & 9.1 & $\mathrm{p}-\mathrm{d}$ & & & 0.007 & & - & - & 0.98 & - & - & & - & - & - & - & 0.95 & - \\
\hline 89 & 264.1244 & 8.7 & p-d & & & & 0.004 & - & - & & - & - & & - & - & - & - & & - \\
\hline 90 & 265.1479 & 13.2 & $\mathrm{n}-\mathrm{d}$ & & 0.001 & & & - & - & & - & - & -0.27 & - & - & - & - & & - \\
\hline 91 & 266.2325 & 10.4 & $\mathrm{p}$ & & & 0.007 & & - & - & -0.02 & - & - & & - & - & - & - & -0.02 & - \\
\hline 92 & 267.9422 & 8.5 & $\mathrm{n}$ & & 0.002 & & 0.001 & - & - & & - & - & 0.54 & - & - & - & - & & - \\
\hline 93 & 272.0560 & 9.2 & $\mathrm{n}$ & & & 0.001 & & - & - & 0.96 & - & - & & - & - & - & - & 0.94 & - \\
\hline 94 & 277.1838 & 14.0 & $\mathrm{n}$ & & & 0.003 & & - & - & 0.00 & - & - & & - & - & - & - & 0.00 & - \\
\hline 95 & 277.1839 & 13.9 & n-d & & & 0.002 & & - & - & 0.01 & - & - & & - & - & - & - & 0.01 & - \\
\hline 96 & 279.0292 & 9.5 & $\mathrm{n}-\mathrm{d}$ & & 0.001 & & & - & - & & - & - & 0.70 & - & - & - & - & & - \\
\hline 97 & 279.1588 & 12.8 & $\mathrm{p}$ & & 0.004 & & & - & - & & - & - & -0.88 & - & - & - & - & & - \\
\hline 98 & 279.1591 & 13.4 & $\mathrm{p}$ & & & 0.016 & & - & - & 0.02 & - & - & & - & - & - & - & 0.03 & - \\
\hline 99 & 279.1591 & 13.4 & $\mathrm{p}-\mathrm{d}$ & 0.001 & & & 0.023 & - & - & & - & - & & - & - & - & - & & - \\
\hline 100 & 282.2792 & 17.6 & $\mathrm{p}$ & & & 0.002 & & - & - & -0.19 & - & - & & - & - & - & - & -0.23 & - \\
\hline 101 & 282.2792 & 17.6 & p-d & 0.001 & & 0.001 & & - & - & -0.03 & - & - & & - & - & - & - & -0.05 & - \\
\hline 102 & 287.2216 & 14.5 & $\mathrm{p}$ & & & 0.001 & & - & - & -0.03 & - & - & & - & - & - & - & -0.03 & - \\
\hline 103 & 291.1995 & 15.0 & $\mathrm{n}$ & & & 0.004 & & - & - & 0.00 & - & - & & - & - & - & - & 0.00 & - \\
\hline 104 & 291.1997 & 14.8 & $\mathrm{n}-\mathrm{d}$ & & & 0.002 & & - & - & 0.00 & - & - & & - & - & - & - & 0.00 & - \\
\hline 105 & 295.9370 & 8.5 & $\mathrm{n}$ & & 0.004 & & 0.002 & - & - & & - & - & 0.54 & - & - & - & - & & - \\
\hline 106 & 297.1528 & 13.1 & $\mathrm{n}$ & 0.001 & 0.001 & 0.002 & 0.001 & - & - & -0.02 & - & - & -0.28 & - & - & - & - & -0.02 & - \\
\hline 107 & 297.1528 & 13.1 & $\mathrm{n}-\mathrm{d}$ & & & 0.002 & & - & - & 0.00 & - & - & & - & - & - & - & 0.00 & - \\
\hline 108 & 299.1251 & 7.5 & $\mathrm{p}-\mathrm{d}$ & & & & 0.012 & - & - & & - & - & & - & - & - & - & & - \\
\hline 109 & 304.2480 & 14.4 & $\mathrm{p}-\mathrm{d}$ & 0.001 & & 0.001 & 0.007 & - & - & -0.01 & - & - & & - & - & - & - & -0.02 & - \\
\hline 110 & 304.2484 & 14.5 & p & & & 0.006 & & - & - & 0.10 & - & - & & - & - & - & - & 0.09 & - \\
\hline 111 & 305.0772 & 8.5 & $\mathrm{n}$ & 0.023 & & 0.013 & & - & - & -0.46 & - & - & & - & - & - & - & -0.59 & - \\
\hline 112 & 305.0774 & 8.5 & $\mathrm{n}-\mathrm{d}$ & & & 0.004 & & - & - & -0.45 & - & - & & - & - & - & - & -0.59 & - \\
\hline 113 & 305.1143 & 8.6 & $\mathrm{p}-\mathrm{d}$ & & & & 0.032 & - & - & & - & - & & - & - & - & - & & - \\
\hline 114 & 305.2153 & 15.7 & $\mathrm{n}$ & & & 0.001 & & - & - & 0.09 & - & - & & - & - & - & - & 0.09 & - \\
\hline 115 & 307.1301 & 12.4 & $\mathrm{p}-\mathrm{d}$ & & & & 0.012 & - & - & & - & - & & - & - & - & - & & - \\
\hline 116 & 311.1683 & 14.2 & $\mathrm{n}$ & & & 0.005 & 0.005 & - & - & -0.01 & - & - & & - & - & - & - & -0.01 & - \\
\hline 117 & 311.1684 & 14.2 & $\mathrm{n}-\mathrm{d}$ & & & 0.010 & & - & - & -0.02 & - & - & & - & - & - & - & -0.02 & - \\
\hline 118 & 311.1689 & 13.9 & $\mathrm{n}$ & 0.004 & 0.005 & & & - & - & & - & - & -0.32 & - & - & - & - & & - \\
\hline 119 & 313.1407 & 7.9 & $\mathrm{p}-\mathrm{d}$ & & 0.001 & & 0.006 & - & - & & - & - & 0.55 & - & - & - & - & & - \\
\hline 120 & 316.0248 & 9.3 & $\mathrm{p}-\mathrm{d}$ & & & & 0.007 & - & - & & - & - & & - & - & - & - & & - \\
\hline 121 & 323.1248 & 8.4 & $\mathrm{p}-\mathrm{d}$ & & & & 0.004 & - & - & & - & - & & - & - & - & - & & - \\
\hline 122 & 323.1248 & 8.9 & $\mathrm{p}-\mathrm{d}$ & & & & 0.007 & - & - & & - & - & & - & - & - & - & & - \\
\hline 123 & 325.1839 & 15.1 & $\mathrm{n}$ & & & 0.006 & 0.004 & - & - & 0.06 & - & - & & - & - & - & - & 0.06 & - \\
\hline 124 & 325.1841 & 15.0 & $\mathrm{n}-\mathrm{d}$ & & & 0.006 & & - & - & 0.01 & - & - & & - & - & - & - & 0.01 & - \\
\hline 125 & 325.1845 & 14.8 & $\mathrm{n}$ & 0.004 & 0.007 & & & - & - & & - & - & -0.37 & - & - & - & - & & - \\
\hline 126 & 327.0045 & 8.4 & $\mathrm{p}-\mathrm{d}$ & & & & 0.017 & - & - & & - & - & & - & - & - & - & & - \\
\hline 127 & 339.1997 & 15.7 & $\mathrm{n}$ & 0.003 & 0.005 & 0.001 & 0.003 & - & - & 0.06 & - & - & -0.72 & - & - & - & - & 0.06 & - \\
\hline 128 & 339.1997 & 15.8 & $n-d$ & & & 0.003 & & - & - & 0.00 & - & - & & - & - & - & - & 0.00 & - \\
\hline 129 & 340.0250 & 9.1 & $\mathrm{p}-\mathrm{d}$ & & 0.004 & & & - & - & & - & - & 0.43 & - & - & - & - & & - \\
\hline 130 & 341.0913 & 14.1 & $\mathrm{p}-\mathrm{d}$ & & 0.002 & & 0.024 & - & - & & - & - & 0.54 & - & - & - & - & & - \\
\hline 131 & 341.0927 & 9.4 & $\mathrm{n}-\mathrm{d}$ & & 0.002 & & & - & - & & - & - & 0.54 & - & - & - & - & & - \\
\hline 132 & 343.1067 & 9.4 & $\mathrm{p}-\mathrm{d}$ & & 0.016 & & 0.147 & - & - & & - & - & 0.54 & - & - & - & - & & - \\
\hline 133 & 343.1652 & 10.2 & $\mathrm{p}$ & & & 0.001 & & - & - & 0.00 & - & - & & - & - & - & - & 0.00 & - \\
\hline 134 & 344.2252 & 15.0 & p-d & & & 0.001 & & - & - & 0.01 & - & - & & - & - & - & - & 0.00 & - \\
\hline 135 & 348.3107 & 17.6 & $\mathrm{p}-\mathrm{d}$ & & & & 0.006 & - & - & & - & - & & - & - & - & - & & - \\
\hline 136 & 360.0390 & 7.8 & $\mathrm{p}-\mathrm{d}$ & & & & 0.003 & - & - & & - & - & & - & - & - & - & & - \\
\hline 137 & 367.1972 & 17.1 & $\mathrm{n}$ & & & 0.004 & & - & - & 0.06 & - & - & & - & - & - & - & 0.05 & - \\
\hline 138 & 423.0733 & 7.5 & $\mathrm{p}-\mathrm{d}$ & & & & 0.005 & - & - & & - & - & & - & - & - & - & & - \\
\hline
\end{tabular}

1. Elucidation of the chemical structures of the TPs corresponding to Peaks \#36, \#38, \#87, \#88, and \#93

The chemical structures of TPs suspected of contributing to the observed mutagenicity were determined as follows. First, an accurate $\mathrm{m} / \mathrm{z}$ value for each peak was determined from the mass spectrum. Second, the chemical formula of the molecular ion $\left([\mathrm{M}+\mathrm{H}]^{+}\right.$in positive-ion mode, $[\mathrm{M}-\mathrm{H}]^{-}$ in negative-ion mode) was determined from the $\mathrm{m} / \mathrm{z}$ value. Information about ions corresponding to 
isotopes of chlorine ([M+2], $[\mathrm{M}+4]$, and so on) obtained from the mass spectrum was also used for determination of the chemical formulas. Third, chemical structures potentially derived from the parent compound (3M4NP) were selected as candidates. Cleavage of benzene rings was not taken into account, and the candidate were selected from compounds having benzene rings. The positions of three side chains that had been originally contained in 3M4NP (i.e., methyl, nitro, and hydroxyl groups) were preserved, if they (or their derivatives) were present. All structures satisfying the assumptions were put on the list of candidate structure. Fourth, we applied a rule-based algorithm for MS/MS analysis to each structure by using the software Mass Frontier 7.0 (HighChem, Bratislava, Slovakia) to calculate the number of fragment ions corresponding to that structure in the tandem mass spectrum (isolation window $=0.4$ ) at a collision energy of $50 \mathrm{eV}$. For each peak, the chemical structure with the largest number of fragment ions assigned to the tandem mass spectrum by the rule-based algorithm was selected as the TP for that peak. When 2 or more chemical structures had the same number of assigned fragment ions, we used a substructure-based algorithm for MS/MS analysis using the web-based software MAGMa (Netherlands Metabolomics Centre, http://www.emetabolomics. org/magma) to assess the structures. By means of MAGMa analysis, we determined the extent to which a candidate structure explained the observed tandem mass spectrum, and we determined a candidate score from the weighted average of the substructure penalty scores. The average was calculated for all bonds of the candidate chemical structure that are disconnected from the substructure, assigned to all fragment ions in the tandem mass spectrum; lower scores correspond to higher plausibility of a chemical structure (Ridder et al. 2012). Finally, the chemical structure with the lowest candidate score was assigned as the TP corresponding to the peak. By using this procedure, we identified the structures of the TPs corresponding to Peaks \#36, \#38, \#87, \#88, and \#93; the assignments of the fragment ions determined by the rule-based algorithm (Mass Frontier) and the substructure-based algorithm (MAGMa) for the 5 peaks are shown in Figs. S2-S6, respectively. The elucidation of the structures of TPs corresponding to Peaks \#24 and \#66 is described sections 2 and 3 of the SI, respectively. 


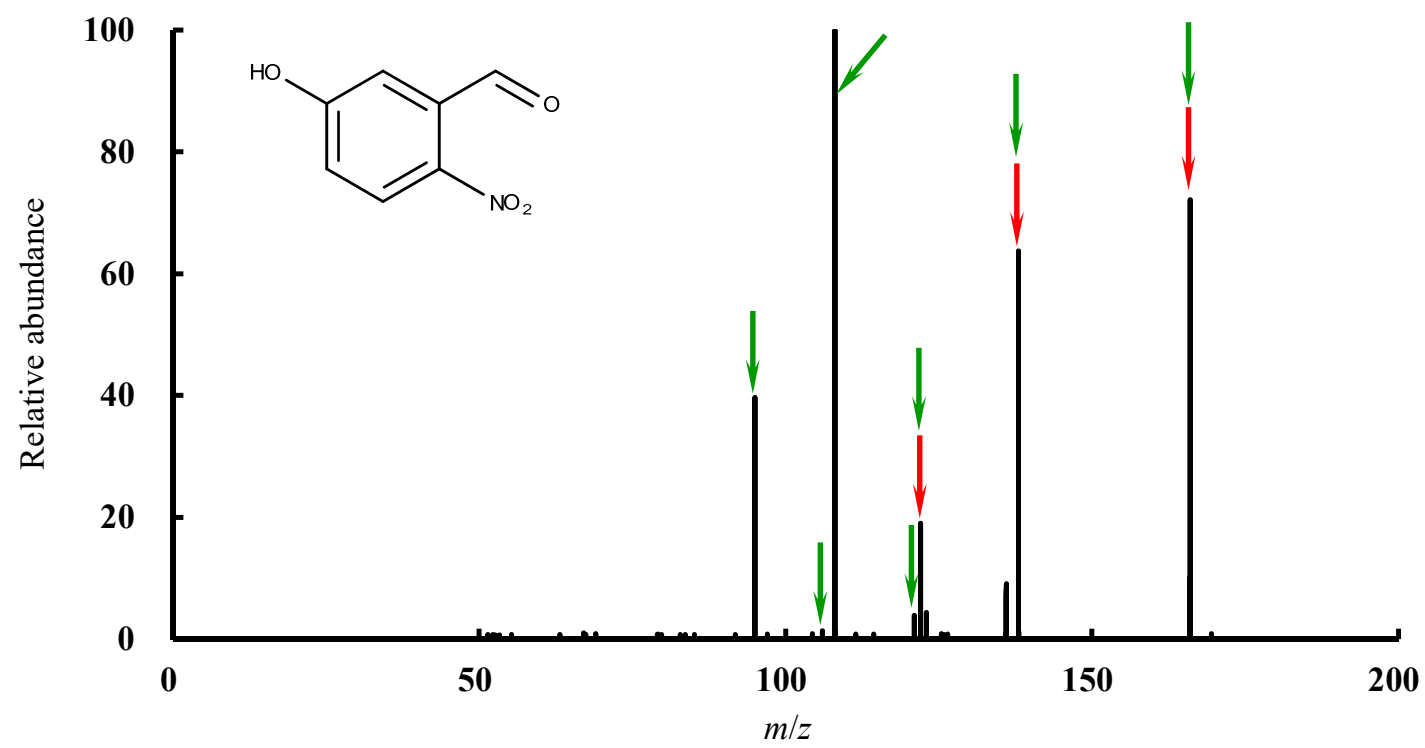

Fig. S2 Assignment of fragment ions in the tandem mass spectrum (negative-ion mode, collision energy $=50 \mathrm{eV})$ of Peak \#36 $(\mathrm{m} / \mathrm{z}=166.0141$, retention time $=7.7 \mathrm{~min})$ and the chemical structure of the transformation product corresponding to this peak. The transformation product corresponding to Peak \#36 was confirmed to be 5-hydroxy-2-nitrobenzaldehyde by comparing its tandem mass spectrum and retention time with those of an authentic sample (see Figs. S12 and S13). Red and green arrows represent fragment ions assigned with Mass Frontier and MAGMa, respectively.

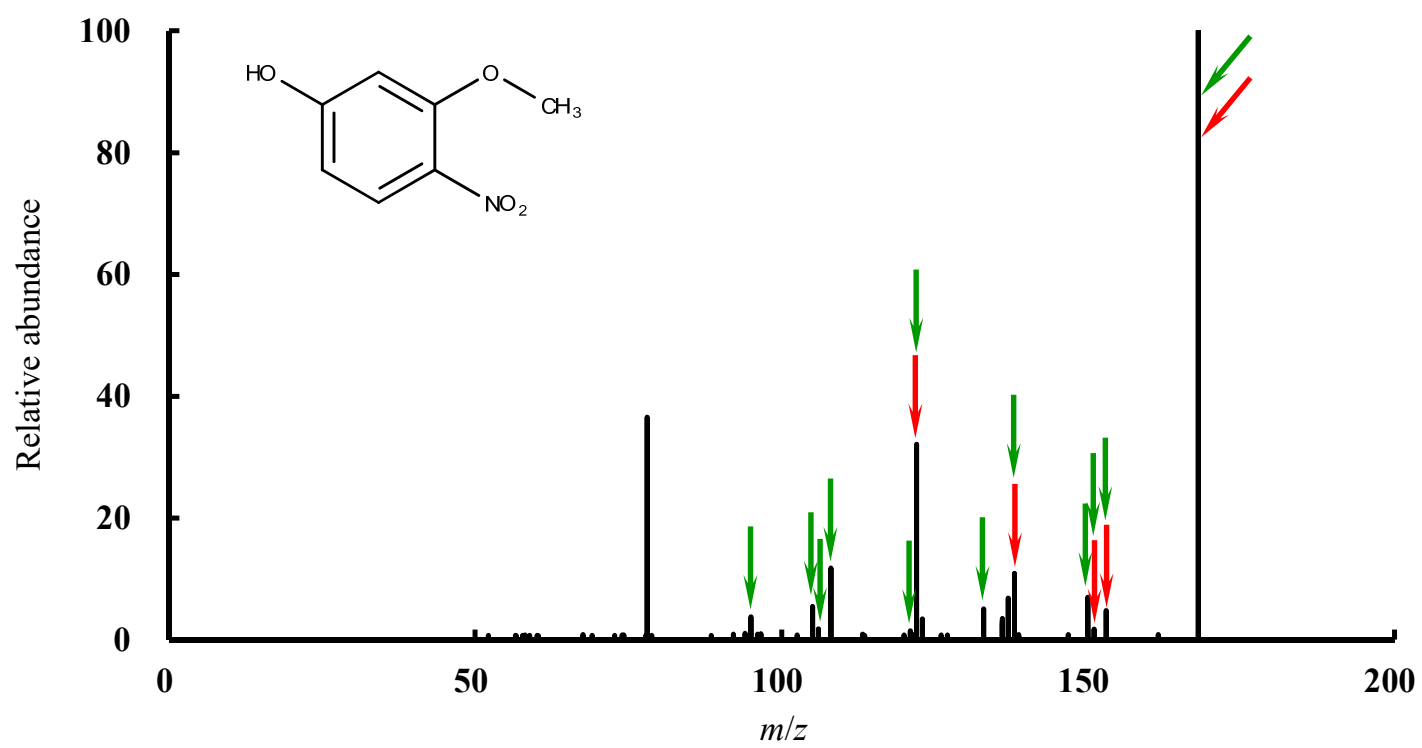

Fig. S3 Assignment of fragment ions in the tandem mass spectrum (negative-ion mode, collision energy $=50 \mathrm{eV})$ of Peak \#38 $(\mathrm{m} / \mathrm{z}=168.0298$, retention time $=7.3 \mathrm{~min})$ and chemical structure of the transformation product corresponding to this peak. Red and green arrows represent fragment ions assigned with Mass Frontier and MAGMa, respectively. 


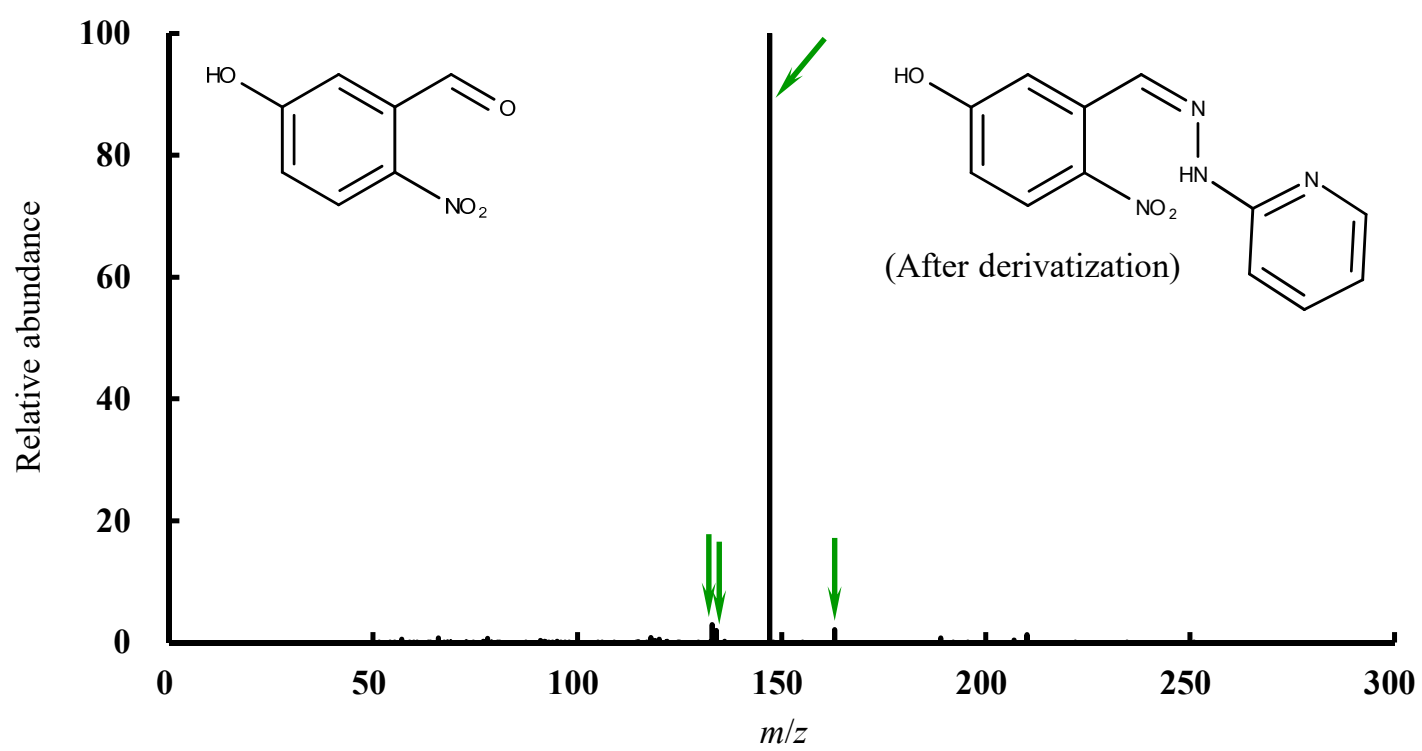

Fig. S4 Assignment of fragment ions in the tandem mass spectrum (negative-ion mode with derivatization, collision energy $=50 \mathrm{eV})$ of Peak $\# 87(\mathrm{~m} / \mathrm{z}=257.0677$, retention time $=9.1 \mathrm{~min})$ and chemical structures of transformation products corresponding to this peak before and after derivatization. The transformation product was confirmed to be 5-hydroxy-2-nitrobenzaldehyde by comparing its tandem mass spectrum and retention time with those of an authentic sample after derivatization (see Figs. S14 and S15). Red and green arrows represent fragment ions assigned with Mass Frontier and MAGMa, respectively.

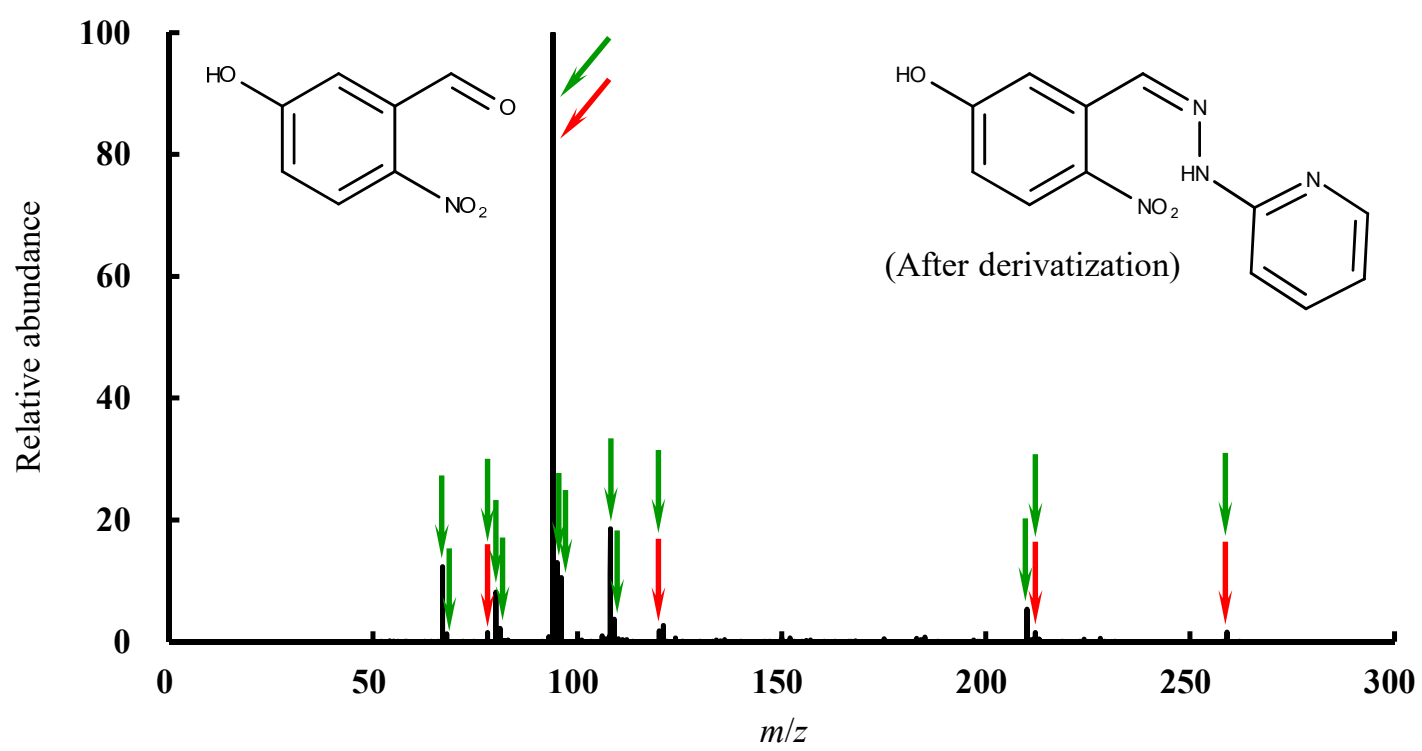

Fig. S5 Assignment of fragment ions in the tandem mass spectrum (positive-ion mode with derivatization, collision energy $=50 \mathrm{eV})$ of Peak $\# 88(\mathrm{~m} / \mathrm{z}=259.0826$, retention time $=9.1 \mathrm{~min})$ and chemical structures of the transformation products corresponding to this peak before and after derivatization. The transformation product was confirmed to be 5-hydroxy-2-nitrobenzaldehyde by comparing its tandem mass spectrum and retention time with those of an authentic sample after derivatization (see Figs. S16 and S17). Red and green arrows represent fragment ions assigned with Mass Frontier and MAGMa, respectively. 


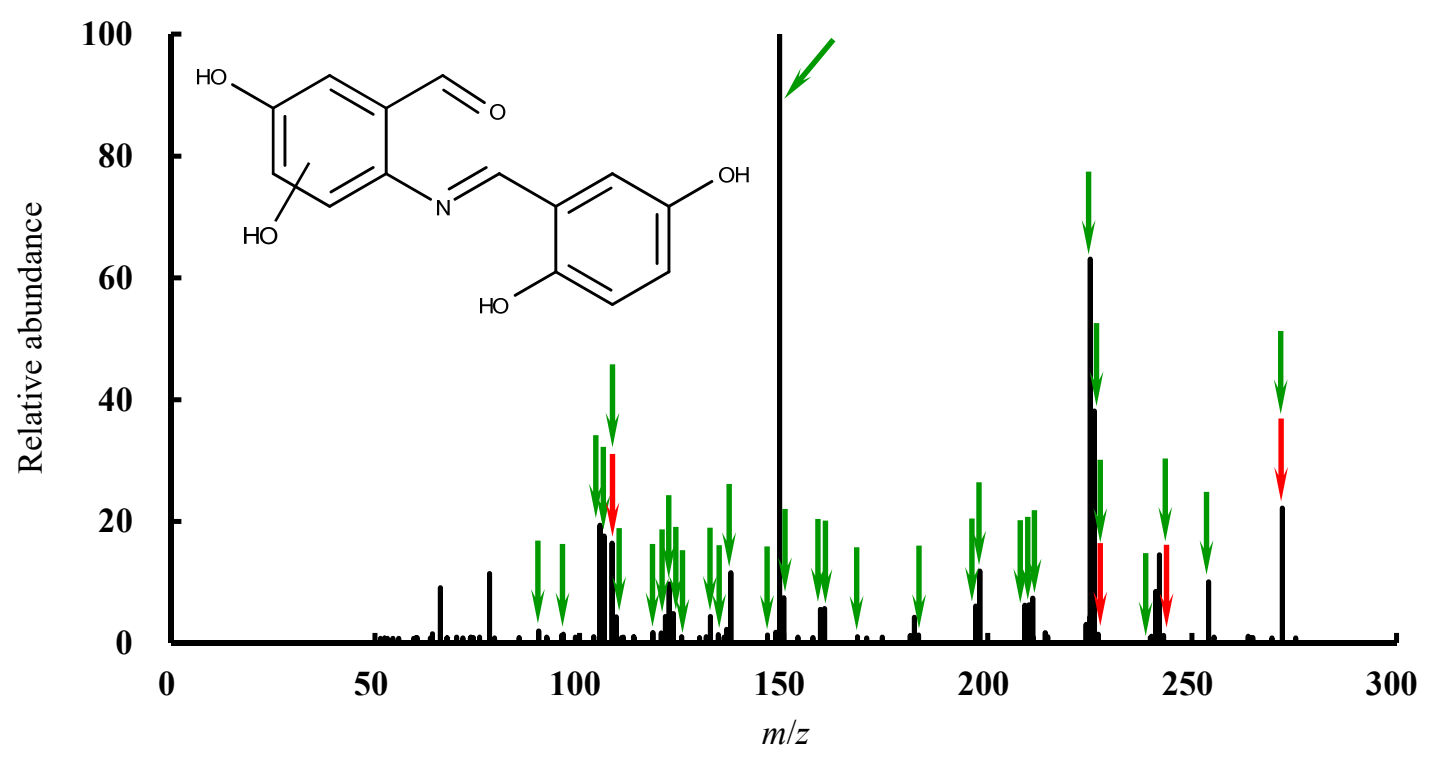

Fig. S6 Assignment of fragment ions in the tandem mass spectrum (negative-ion mode, collision energy $=30 \mathrm{eV})$ of Peak $\# 93(\mathrm{~m} / \mathrm{z}=272.0560$, retention time $=9.2 \mathrm{~min})$ and chemical structure of the transformation product corresponding to this peak. Red and green arrows represent fragment ions assigned with Mass Frontier and MAGMa, respectively.

\section{Determination of the chemical structure of the TP corresponding to Peak \#24}

The accurate $m / z$ value of Peak \#24 in negative-ion mode $\left([\mathrm{M}-\mathrm{H}]^{-}=138.0316\right)$ indicated that the nominal molecular weight of the TP corresponding to this peak was odd (139). Therefore, according to the nitrogen rule, this TP must contain an odd number of nitrogen atoms. On the basis of the accurate $m / z$ value, the 3 most probable chemical formulas were $\mathrm{C}_{7} \mathrm{H}_{7} \mathrm{O}_{3}(\Delta=-4.65 \mathrm{ppm}$, where $\Delta$ is the difference between the observed and expected $m / z$ values), $\mathrm{C}_{5} \mathrm{H}_{5} \mathrm{O}_{2} \mathrm{~N}_{3}\left(\Delta=5.07 \mathrm{ppm}\right.$ ), and $\mathrm{C}_{10} \mathrm{H}_{4} \mathrm{~N}$ $(\Delta=24.5 \mathrm{ppm})$. The first formula contradicted the nitrogen rule because it contained no nitrogen atoms. Although the second formula satisfied the rule, the number of carbon atoms suggested by the $[\mathrm{M}-\mathrm{H}-1]^{-} /[\mathrm{M}-\mathrm{H}]^{-}$ratio $(7.6 \%)$ was 7 , whereas the proposed formula contained only 5 carbon atoms. The third formula also satisfied the nitrogen rule, but its $\Delta$ value was too large.

Therefore, we speculated that $m / z=138.0316$ (Peak \#24) was not a molecular ion but rather a TP fragment ion generated by unintentional in-source collision-induced dissociation. In fact, a peak with $\mathrm{m} / \mathrm{z}=168.0298$ (Peak \#S1) was observed at the same retention time as Peak \#24 (8.8 min) (Fig. S7). Moreover, the mass spectra of these 2 peaks were almost the same except for the presence of the molecular ion in the spectra of Peak \#S1 $(\mathrm{m} / \mathrm{z}=168.0298$, Fig. S8). These 2 facts suggested that the ion observed at $\mathrm{m} / \mathrm{z}=138.0316$ and corresponding to Peak \#24 was a fragment ion derived from the compound corresponding to Peak \#S1 ( $\mathrm{m} / \mathrm{z}=168.0298)$. 

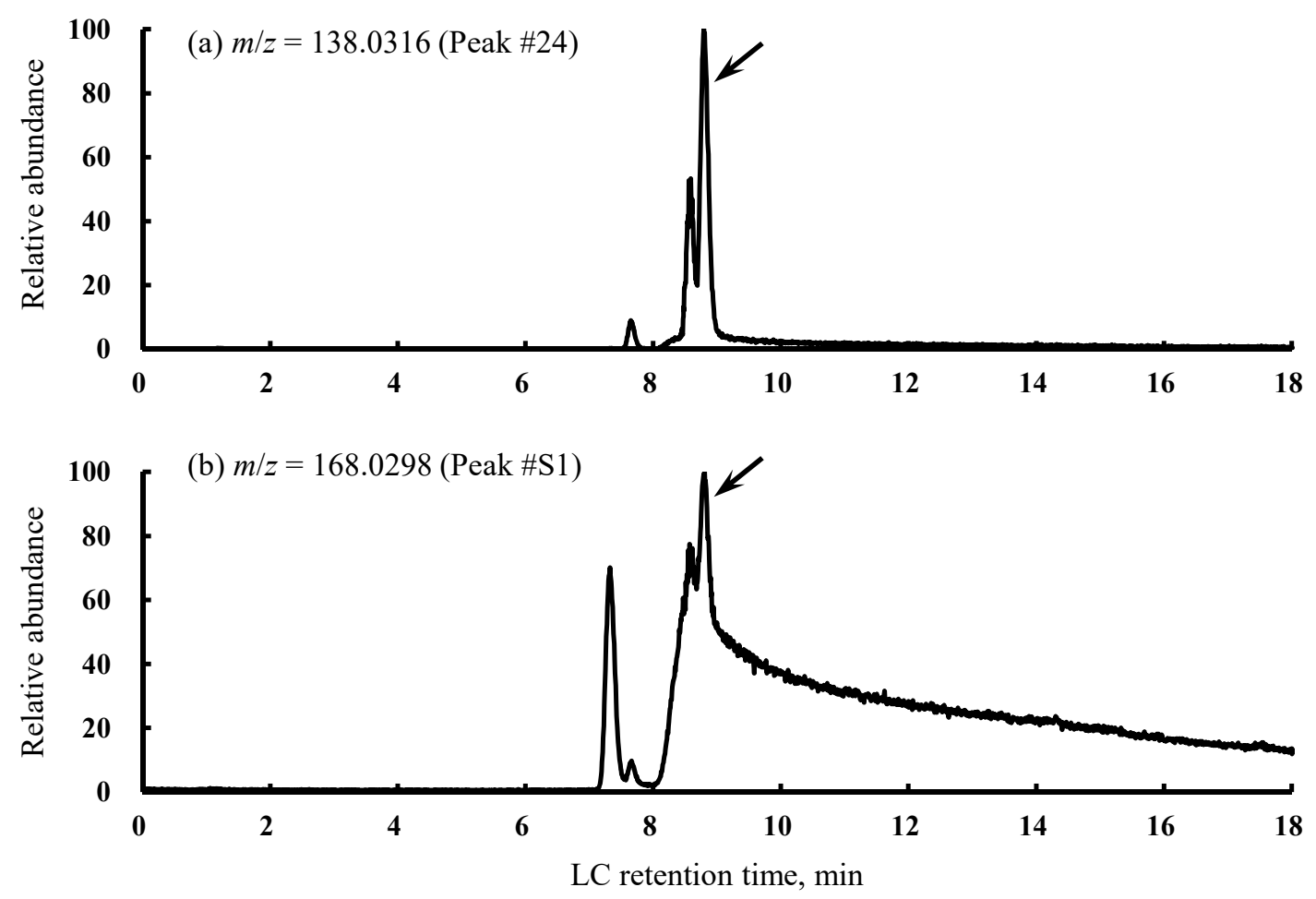

Fig. S7 Comparison of selected-ion-monitoring charts for $m / z=138.0316$ (Peak \#24) and $\mathrm{m} / \mathrm{z}=$ 168.0298 (Peak \#S1). Peaks marked with arrows were analyzed by tandem mass spectrometry (Fig. S8). 

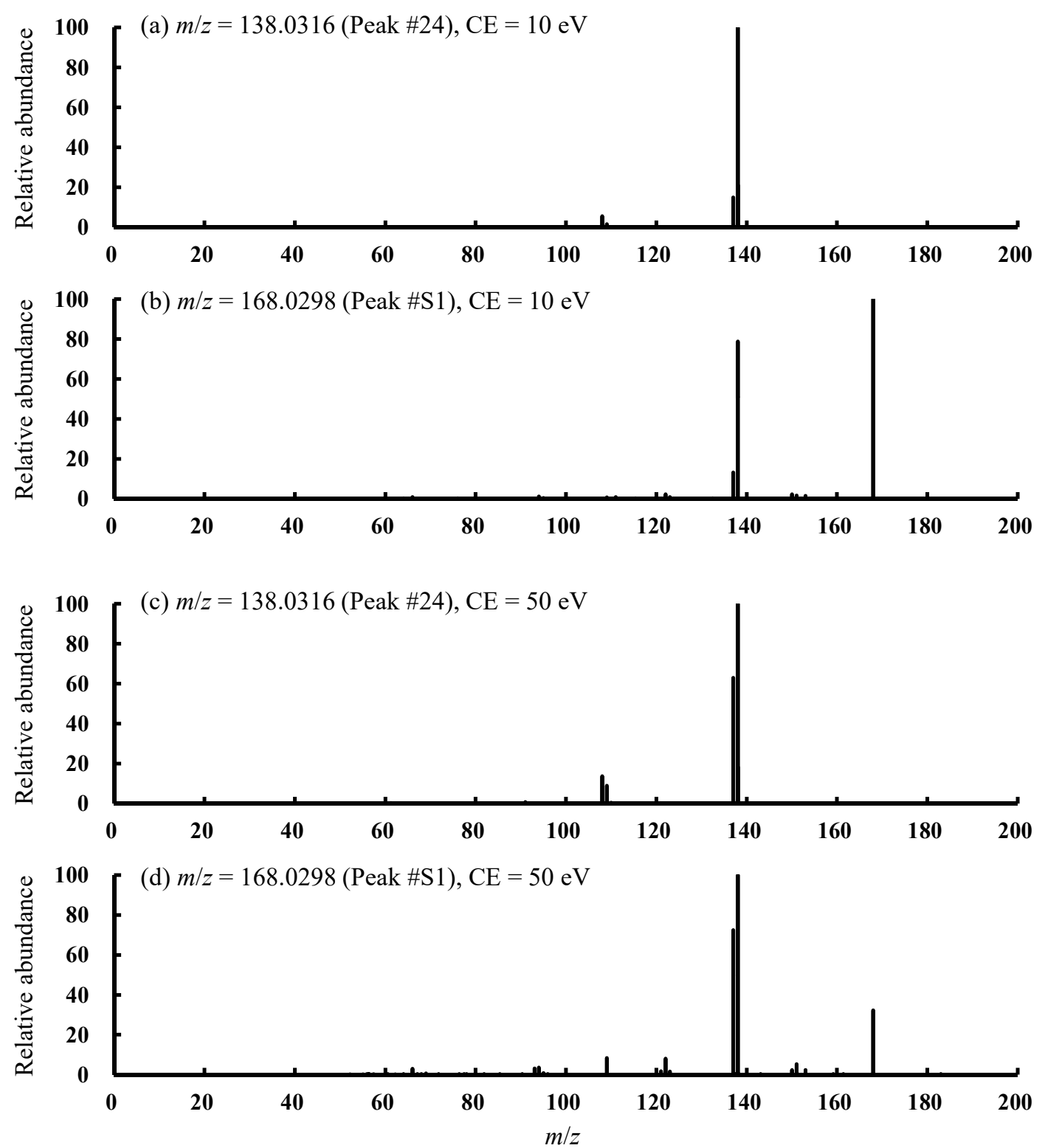

Fig. S8 Comparison of tandem mass spectra (negative-ion mode) of $m / z=138.0316$ (Peak \#24) and $m / z=168.0298($ Peak $\#$ S1) at collision energies (CEs) of 10 and $50 \mathrm{eV}$.

By the procedure described in section 1 of the SI, the TP corresponding to Peak \#S1 was assigned as 3-methoxy-4-nitrophenol (Fig. S9). Accordingly, we also assigned the TP corresponding to Peak \#24 as 3-methoxy-4-nitrophenol. 


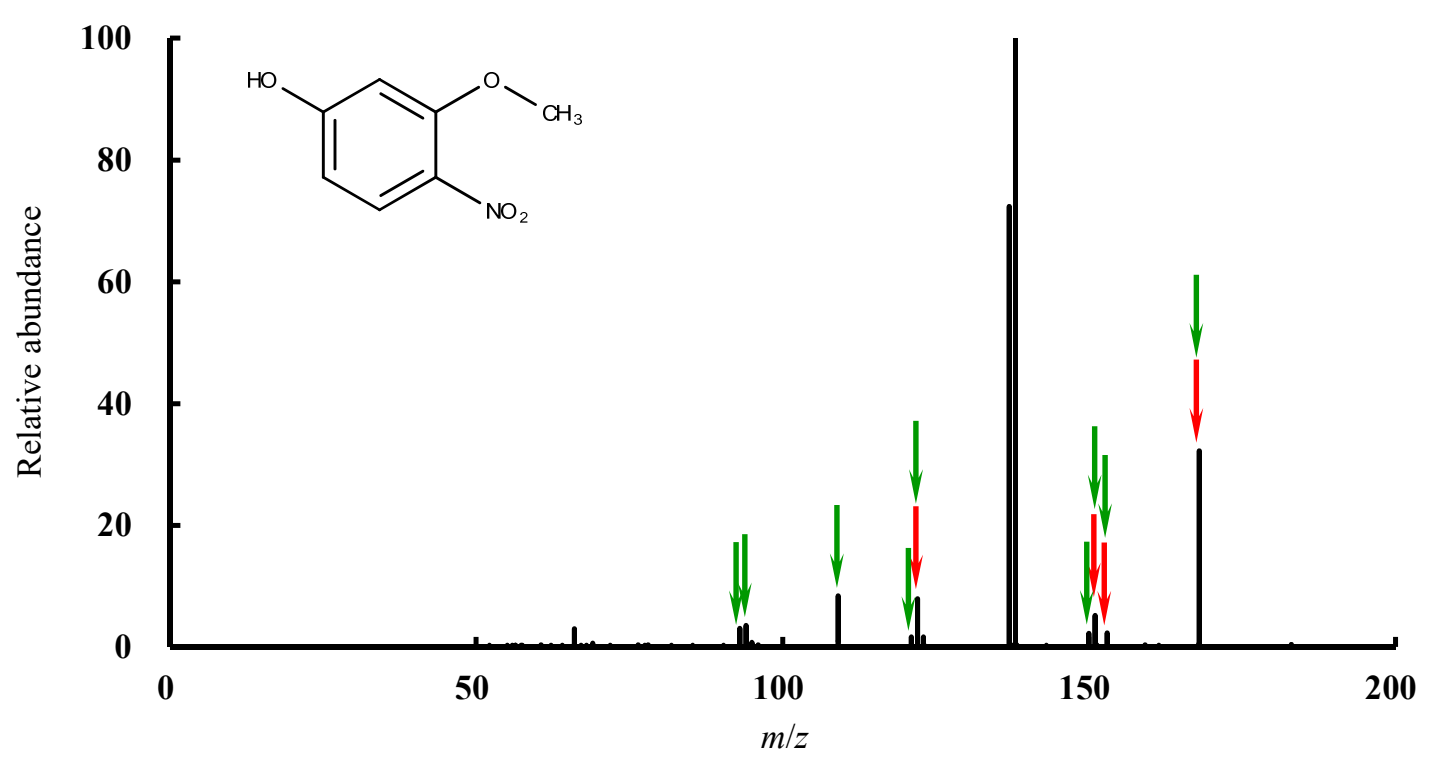

Fig. S9 Assignment of fragment ions in the tandem mass spectrum (negative-ion mode, collision energy $=50 \mathrm{eV})$ of Peak $\# \mathrm{~S} 1(\mathrm{~m} / \mathrm{z}=168.0298$, retention time $=8.8 \mathrm{~min})$ and chemical structure of the transformation product corresponding to this peak. Red and green arrows represent fragment ions assigned with Mass Frontier and MAGMa, respectively.

\section{Assignment of the chemical structure of the TP corresponding to Peak \#66}

MS/MS analysis of Peak \#66 $(\mathrm{m} / \mathrm{z}=219.9574)$ revealed that the TP corresponding to this peak in negative-ion mode with derivatization was a chloro-3-(chloromethyl)-4-nitrophenol (Fig. S10), which would not have undergone derivatization. The retention time of Peak \#66 (8.2 min) was nearly identical to that of Peak \#65 $(\mathrm{m} / \mathrm{z}=219.9573)$, and the $\mathrm{m} / \mathrm{z}$ value and tandem mass spectrum of Peak \#65 (Fig. S11) were almost the same as those of Peak \#66, which was detected in negative-ion mode without derivatization. These observations indicate that the TPs corresponding to Peaks \#65 and \#66 were the same. However, we had already removed the TP corresponding to Peak \#65 from the list of candidate mutagens, as described in section 3.5 of the main text: the area of Peak \#65 strongly correlated with the observed mutagenicity of the $\mathrm{O}_{3} / \mathrm{Cl}$ sample in the TA98 assay with metabolic activation $\left(r^{2}=0.89\right)$, whereas the $\mathrm{AOP} / \mathrm{Cl}$ sample was not mutagenic under the same Ames conditions even though the maximum peak areas for Peak \#65 were roughly the same for $\mathrm{O}_{3} / \mathrm{Cl}(\mathrm{MPA}$ $=0.100)$ and $\mathrm{AOP} / \mathrm{Cl}(\mathrm{MPA}=0.061)$. These results indicate that the TP corresponding to Peak \#66 was unlikely to have contributed to the observed mutagenicity. 


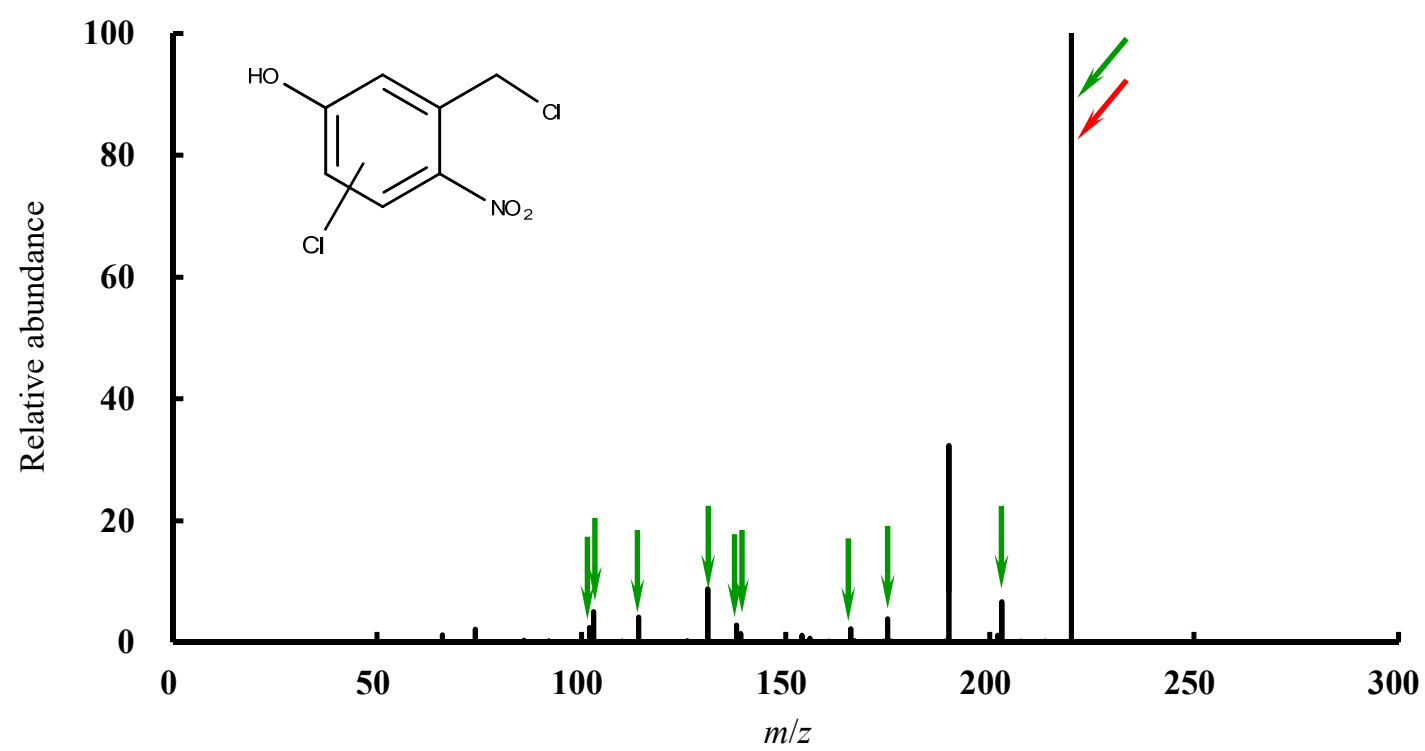

Fig. S10 Assignment of fragment ions in the tandem mass spectrum (negative-ion mode with derivatization, collision energy $=50 \mathrm{eV})$ of Peak $\# 66(\mathrm{~m} / \mathrm{z}=219.9574$, retention time $=8.2 \mathrm{~min})$ and chemical structure of the transformation product corresponding to this peak. Red and green arrows represent fragment ions assigned with Mass Frontier and MAGMa, respectively.

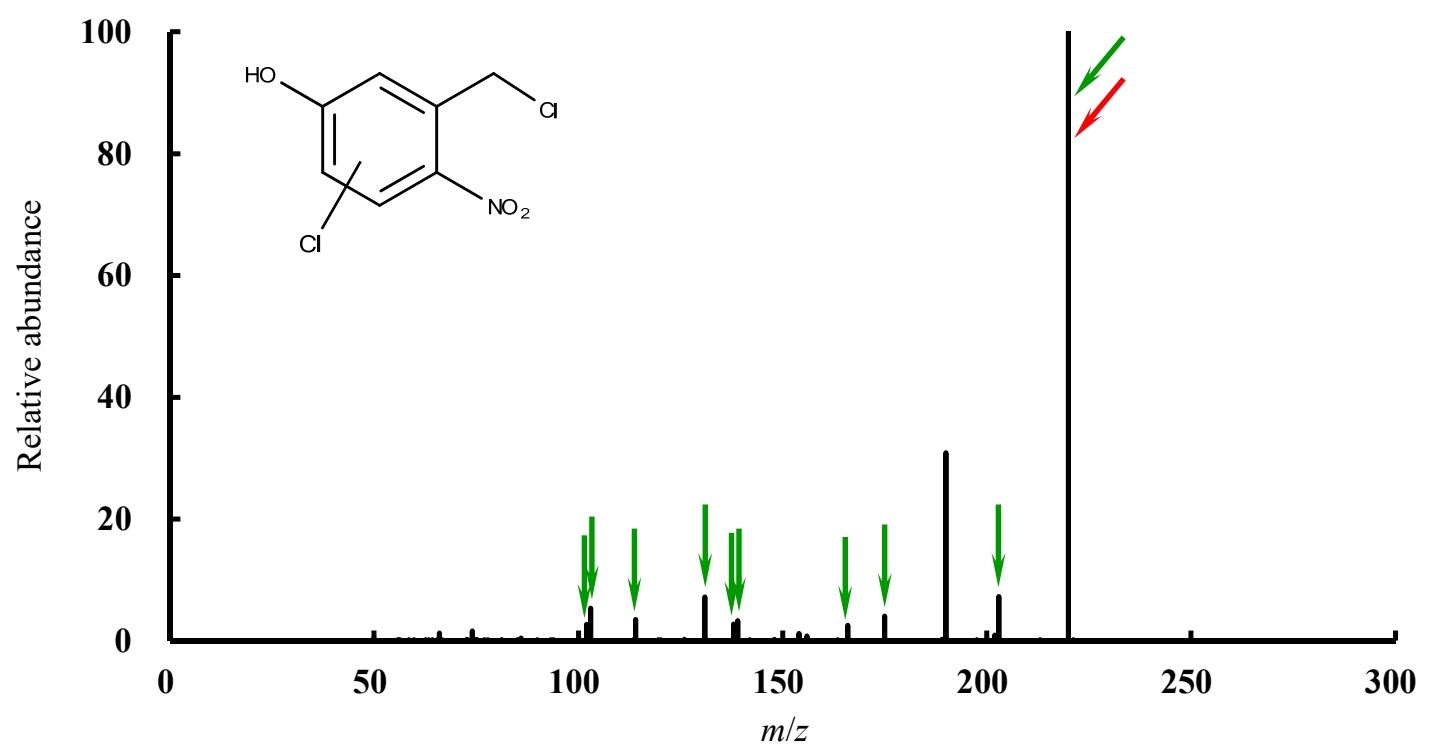

Fig. S11 Assignment of fragment ions in the tandem mass spectrum (negative-ion mode, collision energy $=50 \mathrm{eV})$ of Peak $\# 65(\mathrm{~m} / \mathrm{z}=219.9573$, retention time $=8.2 \mathrm{~min})$ and chemical structure of the transformation product corresponding to this peak. Red and green arrows represent fragment ions assigned with Mass Frontier and MAGMa, respectively.

4. Comparison of LC retention times and tandem mass spectra of Peaks \#36, \#87, and \#88 with those of a commercially available standard

The TP corresponding to Peaks \#36, \#87, and \#88 was assigned as 5-hydroxy-2-nitrobenzaldehyde, which is commercially available. To confirm our assignment of these peaks, we compared the LC retention times and mass spectra of the experimental sample with those of an authentic sample of 5- 
hydroxy-2-nitrobenzaldehyde (Figs. S12-S17). The LC retention times and mass spectra of the experimental and authentic samples were identical, confirming that the TP corresponding to Peaks \#36, \#87, and \#88 was 5-hydroxy-2-nitrobenzaldehyde.
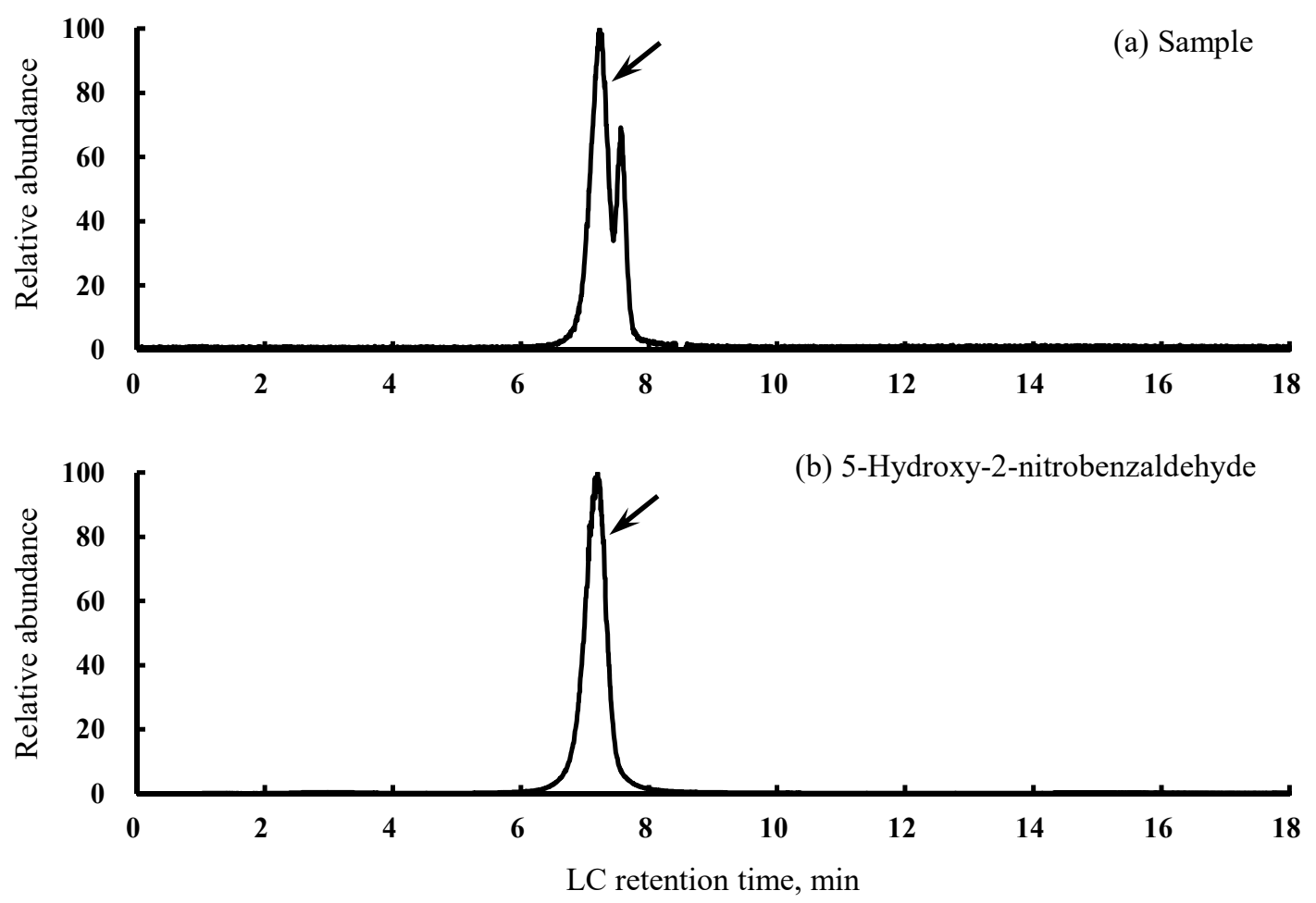

Fig. S12 Comparison of selected-ion-monitoring charts $(\mathrm{m} / \mathrm{z}=166.0141$, negative-ion mode) for the experimental sample (Peak \#36) and for an authentic sample of 5-hydroxy-2-nitrobenzaldehyde. Peaks marked with arrows were analyzed by tandem mass spectrometry (Fig. S13). 

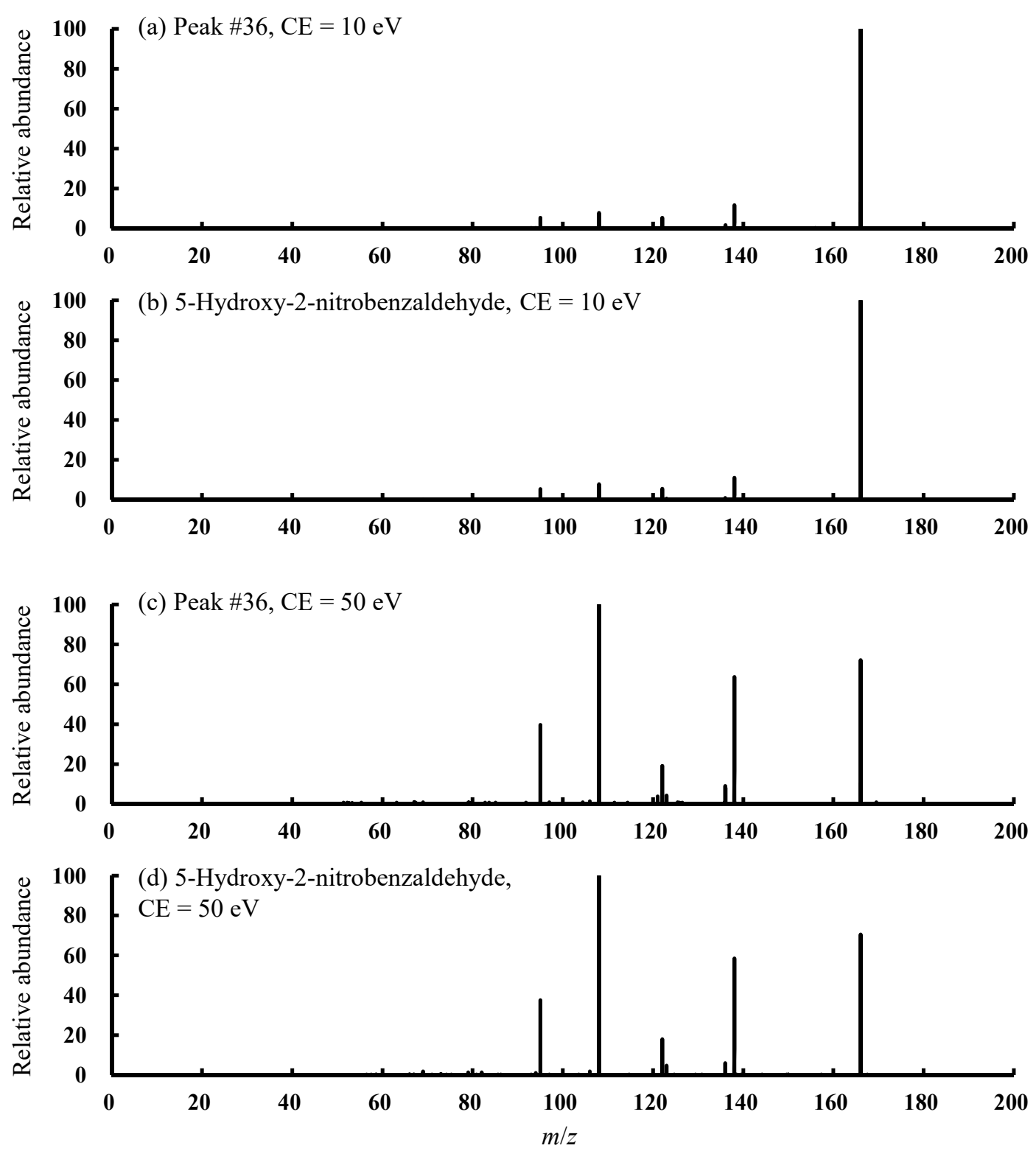

Fig. S13 Comparison of tandem mass spectra of Peak \#36 ( $\mathrm{m} / \mathrm{z}=166.0141$, negative-ion mode $)$ and spectra of an authentic sample of 5-hydroxy-2-nitrobenzaldehyde at collision energies (CEs) of 10 and $50 \mathrm{eV}$. 

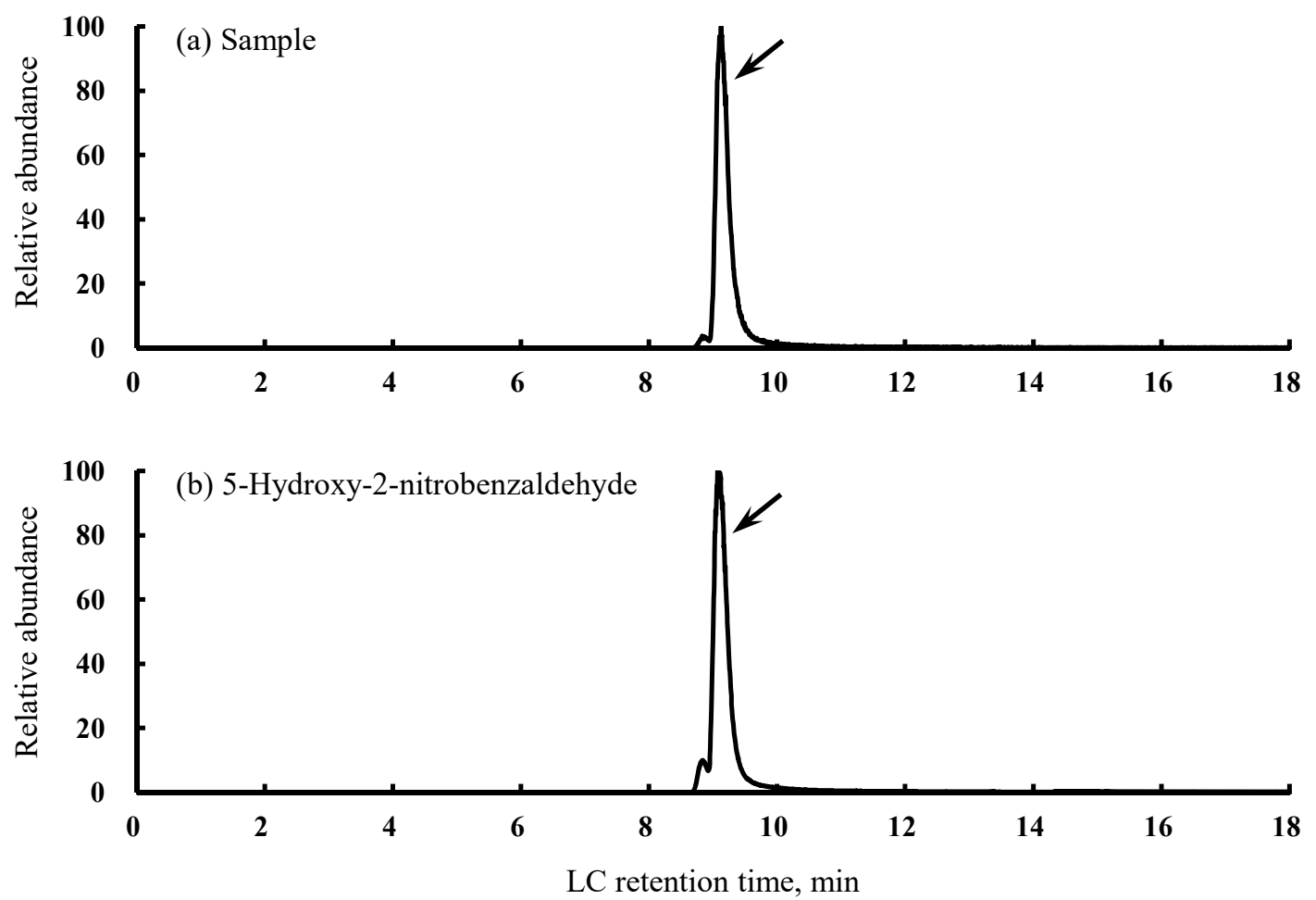

Fig. S14 Comparison of selected-ion-monitoring charts $(\mathrm{m} / \mathrm{z}=257.0677$, negative-ion mode) for the derivatized experimental sample (Peak \#87) and an authentic sample of 5-hydroxy-2nitrobenzaldehyde. Peaks marked with arrows were analyzed by tandem mass spectrometry (Fig. S15). 

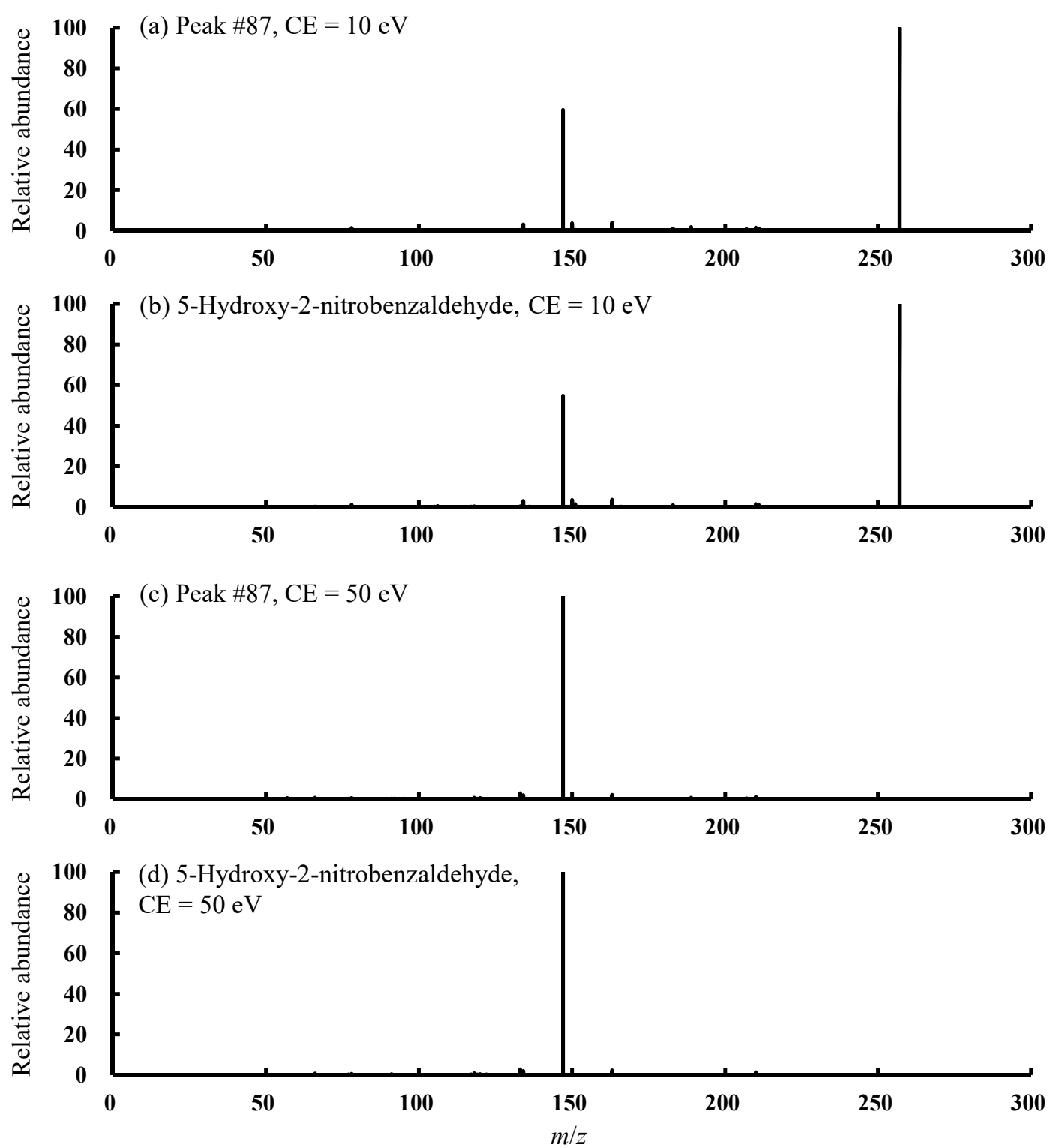

Fig. S15 Comparison of tandem mass spectra of Peak \#87 ( $\mathrm{m} / \mathrm{z}=257.0677$, negative-ion mode with derivatization) and spectra of a derivatized authentic sample of 5-hydroxy-2-nitrobenzaldehyde at collision energies (CEs) of 10 and $50 \mathrm{eV}$. 

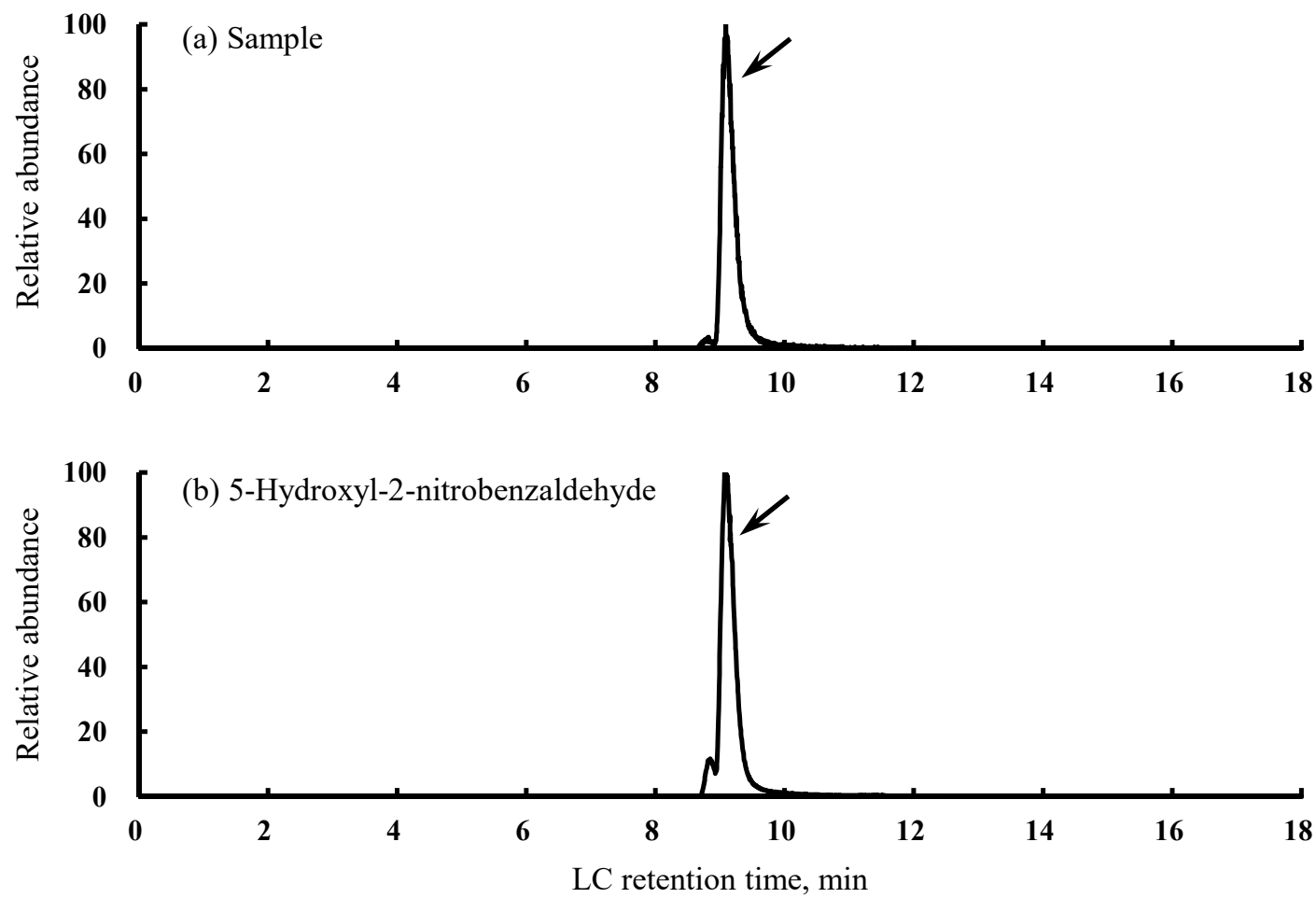

Fig. S16 Comparison of selected-ion-monitoring charts $(\mathrm{m} / \mathrm{z}=259.0826$, positive-ion mode) for the derivatized experimental sample (Peak \#88) and a derivatized authentic sample of 5-hydroxy-2nitrobenzaldehyde. Peaks marked with arrows were analyzed by tandem mass spectrometry (Fig. S17). 

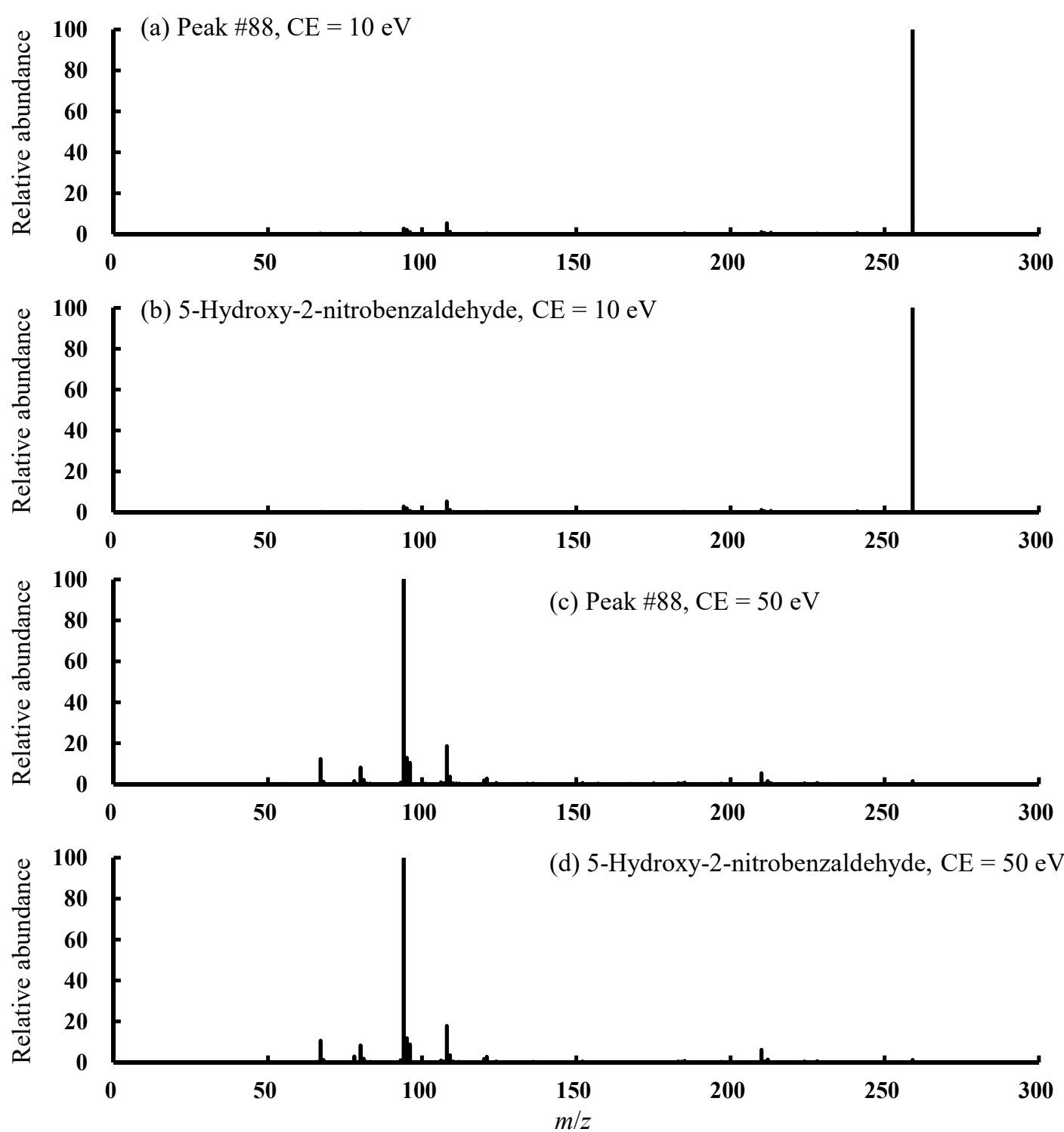

Fig. S17 Comparison of tandem mass spectra of Peak \#88 (m/z=259.0826, positive-ion mode with derivatization) and spectra of a derivatized authentic sample of 5-hydroxy-2-nitrobenzaldehyde at collision energies (CEs) of 10 and $50 \mathrm{eV}$.

\section{References}

Hala, D., Overturf, M.D., Petersen, L.H. and Huggett, D.B. (2011) Quantification of 2hydrazinopyridine derivatized steroid hormones in fathead minnow (Pimephales promelas) blood plasma using LC-ESI+/MS/MS. Journal of Chromatography B 879(9-10), 591-598.

Higashi, T., Shibayama, Y., Ichikawa, T., Ito, K., Toyo’oka, T., Shimada, K., Mitamura, K., Ikegawa, S. and Chiba, H. (2010) Salivary chenodeoxycholic acid and its glycine-conjugate: Their determination method using LC-MS/MS and variation of their concentrations with increased saliva flow rate. Steroids 75(4-5), 338-345.

Ridder, L., van der Hooft, J.J.J., Verhoeven, S., de Vos, R.C.H., van Schaik, R. and Vervoort, J. (2012) Substructure-based annotation of high-resolution multistage $\mathrm{MS}^{n}$ spectral trees. Rapid Communications in Mass Spectrometry 26(20), 2461-2471. 